\title{
A review of wave celerity in frictionless and axisymmetrical steel-lined pressure tunnels
}

\author{
F.E. Hachem *, A.J. Schleiss \\ Laboratory of Hydraulic Constructions, Ecole Polytechnique Fédérale de Lausanne, Station 18, 1015 Lausanne, Switzerland
}

\section{A R T I C L E I N F O}

\section{Article history:}

Received 3 November 2009

Accepted 6 November 2010

Available online 22 December 2010

\section{Keywords:}

Water hammer

Steel-lined pressure tunnels

Quasi-static wave speed

Frequency-dependent wave speed

Fluid-structure interaction

\begin{abstract}
A B S T R A C T
Generally applicable approaches for estimating the "quasi-static", which means without fluid-structure interaction and frequency-dependent water-hammer wave speed in steel-lined pressure tunnels are analyzed. The external constraints and assumptions of these approaches are discussed in detail. The reformulated formulas are then compared to commonly used expressions. Some special cases of wave speed calculation such as unlined pressure tunnels and open-air penstocks are investigated. The quasi-static wave speed is significantly influenced by the state of the backfill concrete and the near-field rock zone (cracked or uncracked). In the case when these two layers are cracked, the quasi-static wave speed is overestimated in between $1 \%$ and $8 \%$ compared to uncracked concrete and near-field rock layers. Depending on the stiffness of steel liner and penstock, the fluid-structure interaction leads to significant difference in wave speeds values. Compared to the quasi-static case, the fluid-structure interaction approach, applied to steel-lined tunnels, results up to $13 \%$ higher wave speed values in the high-frequency range (higher than $600 \mathrm{~Hz}$ ) and up to $150 \%$ lower values for frequencies between 150 and $300 \mathrm{~Hz}$ in the considered test case.
\end{abstract}

(c) 2010 Elsevier Ltd. All rights reserved.

\section{Introduction}

The quasi-static and frequency-dependent wave speed of flow disturbances in pipes have been treated extensively for rigid, elastic and visco-elastic tube walls. Without considering fluid-structure interaction (FSI), Halliwell (1963), Streeter (1963), Rieutord (1982), Wylie et al. (1993), and Ghidaoui et al. (2005) gave, among others, good overviews on the different methods for wave speed estimation. FSI can be found in Rubinov and Keller (1971, 1978), Lavooij and Tijsseling (1991), and Tijsseling (1996). Unlike the case of open-air and thin-walled pipes, most formulae predicting the wave speed of flow disturbances in rock-bored tunnels and shafts (lined or unlined) have not been explicitly derived using a clear definition of the external constraints. The most consistent approaches, without considering the FSI problem, can be found in Jaeger (1933), Halliwell (1963), Fanelli (1973), Bürmann (1975), and Suo and Wylie (1990a). Considering FSI, references from the biomechanical domain such as Atabeck (1968) and Kuiken $(1984,1988)$ provide a rather complete 2-D calculation model. A 1-D mathematical model was also presented by Tijsseling (2007) describing the behaviour of thick-walled and liquidfilled pipes.

This paper focuses on the analysis of the wave speed propagation in rock-bored steel-lined tunnels and shafts. The purpose of it is to give: (a) a review of relevant contributions in deriving the wave speed formulae with clear definition of hypotheses

\footnotetext{
* Corresponding author.

E-mail addresses: fadi.hachem@epfl.ch, fadi.hachem@a3.epfl.ch (F.E. Hachem).
} 


\begin{tabular}{|c|c|c|c|}
\hline \multicolumn{2}{|c|}{ Nomenclature } & \multirow{2}{*}{$\begin{array}{l}p_{0} \\
p_{c}\end{array}$} & \multirow{2}{*}{$\begin{array}{l}\text { water pressure in the steady-state conditions } \\
\text { used in the FSI case (MPa) } \\
\text { pressure transmitted to backfill concrete at } \\
\text { radius } r_{c}(\mathrm{MPa})\end{array}$} \\
\hline$a$ & $\begin{array}{l}\text { quasi-static wave speed of water hammer } \\
(\mathrm{m} / \mathrm{s})\end{array}$ & & \\
\hline A & $\begin{array}{l}\text { internal cross-sectional area of the steel liner } \\
\left(\mathrm{m}^{2}\right)\end{array}$ & $p_{i}$ & $\begin{array}{l}\text { water pressure used in the quasi-static } \\
\text { case (MPa) }\end{array}$ \\
\hline $\begin{array}{l}A_{1}, A_{2} \\
A_{3}, A_{4}\end{array}$ & $\begin{array}{l}\text { factors defined in Eq. }(3.3) \\
\text { factors defined in }\end{array}$ & $p_{r 1}$ & $\begin{array}{l}\text { uniform pressure transmitted to the rock zone } \\
\text { at radius } r_{a}(\mathrm{MPa})\end{array}$ \\
\hline & & $p_{r 2}$ & $\begin{array}{l}\text { uniform pressure transmitted to the rock zone } \\
\text { at radius } r_{f}(\mathrm{MPa})\end{array}$ \\
\hline $\begin{array}{l}A_{5}, A_{6} \\
b\end{array}$ & $\begin{array}{l}\text { tunnel and the steel-liner thickness }\left(=p_{i} / t_{s}\right) \\
(-)\end{array}$ & $\begin{array}{l}r \\
r_{c} \\
r_{f}\end{array}$ & $\begin{array}{l}\text { radius measured from tunnel axis }(\mathrm{m}) \\
\text { internal radius of backfill concrete }(\mathrm{m}) \\
\text { internal radius of the far-field rock zone }(\mathrm{m})\end{array}$ \\
\hline c & complex wave speed $(\mathrm{m} / \mathrm{s})$ & $r_{a}$ & internal radius of the near-field rock zone ( $\mathrm{m}$ ) \\
\hline$c_{0 \text { eq }}$ & $\begin{array}{l}\text { equivalent reference wave speed defined in } \\
\text { Eq. }(4.6)(\mathrm{m} / \mathrm{s})\end{array}$ & $\begin{array}{l}r_{i} \\
t\end{array}$ & $\begin{array}{l}\text { internal radius of the steel liner }(\mathrm{m}) \\
\text { time }(\mathrm{s})\end{array}$ \\
\hline$c_{i}$ & phase or group velocities of the $i$ th mode $(\mathrm{m} / \mathrm{s})$ & $t_{s}$ & steel liner or penstock wall thickness (m) \\
\hline$c_{g i}$ & $\begin{array}{l}\text { group velocity of the } i \text { th mode }(\mathrm{m} / \mathrm{s}) \\
\text { phase velocity of the } i \text { th mode }(\mathrm{m} / \mathrm{s})\end{array}$ & $u$ & $\begin{array}{l}\text { water velocity in the axial direction of the } \\
\text { tunnel }(\mathrm{m} / \mathrm{s})\end{array}$ \\
\hline$c_{0}$ & ave speed $(\mathrm{m} / \mathrm{s})$ & $u_{l}^{s}$ & axial displacement of the steel liner (m) \\
\hline$c_{T}$ & and in unconfined water $(\mathrm{m} / \mathrm{s})$ & $u_{r}^{s}$ & radial displace \\
\hline$C_{r, l}$ & $\begin{array}{l}\text { radial (longitudinal) frictional coefficient per } \\
\text { unit area of the Kelvin model }\left(\mathrm{N} \mathrm{s} / \mathrm{m} / \mathrm{m}^{2}\right)\end{array}$ & $v$ & $\begin{array}{l}\text { water velocity in the radial direction of the } \\
\text { tunnel }(\mathrm{m} / \mathrm{s})\end{array}$ \\
\hline 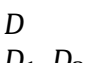 & complex integration constant $(-)$ & $x$ & inal coordinate according to the tun- \\
\hline$D_{1}, D_{2}$ & $\begin{array}{l}\text { undetermined complex constants of solution } \\
(-)\end{array}$ & $\Delta_{i}$ & nic decrement of the $i$ th propagating \\
\hline $\begin{array}{l}D \\
E_{\mathrm{app}} \\
E_{c}\end{array}$ & $\begin{array}{l}\text { q. }(2.19) \\
\text { ass (MPa) } \\
\text { rete }\end{array}$ & $\Delta r_{0}$ & $\begin{array}{l}\text { initial thermal gap between steel liner and } \\
\text { backfill concrete }(\mathrm{m})\end{array}$ \\
\hline & & $\zeta$ & damping ratio for the Kelvin model $(-)$ \\
\hline $\begin{array}{l}E_{s} \\
E_{c r m}\end{array}$ & elasticity modulus of steel liner (MPa) & $\lambda_{i}$ & wave length of the $i$ th propagating mode \\
\hline & $\begin{array}{l}\text { elasticity modulus of the near-field loosened } \\
\text { rock zone (MPa) }\end{array}$ & $\mu$ & dynamic viscosity of water $(\mathrm{kg} / \mathrm{m} / \mathrm{s})$ \\
\hline$E_{\mathrm{rm}}$ & $\begin{array}{l}\text { elasticity modulus of the far-field rock } \\
\text { zone (MPa) }\end{array}$ & $\begin{array}{l}v_{c} \\
v_{s}\end{array}$ & $\begin{array}{l}\text { Poisson's ratio of backfill concrete }(-) \\
\text { Poisson's ratio of steel }(-)\end{array}$ \\
\hline$F_{x}$ & $\begin{array}{l}\text { resultant of axial forces applied on the liner per } \\
\text { unit area }\left(\mathrm{MN} / \mathrm{m}^{2}\right)\end{array}$ & $v_{\mathrm{rm}}$ & $\begin{array}{l}\text { Poisson's ratio of the near-and far-fields of the } \\
\text { rock mass }(-)\end{array}$ \\
\hline$F_{r}$ & $\begin{array}{l}\text { resultant of radial forces applied on the liner } \\
\text { per unit area }\left(\mathrm{MN} / \mathrm{m}^{2}\right)\end{array}$ & $\rho_{w}$ & $\begin{array}{l}\text { unit mass of water used in the quasi-static case } \\
\left(\mathrm{kg} / \mathrm{m}^{3}\right)\end{array}$ \\
\hline$f$ & excitation frequency $(\mathrm{Hz})$ & $\sigma_{r}$ & $\begin{array}{l}\text { radial stress in the theory of thick-walled } \\
\text { cylinder }(\mathrm{MN} / \mathrm{m})\end{array}$ \\
\hline $\begin{array}{l}f_{y} \\
\mathrm{i}\end{array}$ & $\begin{array}{l}\text { yield strength of steel (MPa) } \\
\text { the complex number }(-1)^{0.5}\end{array}$ & $\sigma_{t}$ & tensile stress in the theory of thick-walled \\
\hline$k$ & $\begin{array}{l}\text { ratio of the reference wave speed }\left(c_{0}\right) \text { to the } \\
\text { complex wave speed }(c)(-)\end{array}$ & $\sigma_{l}^{0}$ & $\begin{array}{l}\text { cylinder }(\mathrm{MN} / \mathrm{m}) \\
\text { initial longitudinal stress in the liner per unit }\end{array}$ \\
\hline$K_{r}$ & parameter defined in Eq. (4.4) $(\mathrm{N} / \mathrm{m})$ & & \\
\hline$K s_{r, l}$ & $\begin{array}{l}\text { radial (resp. longitudinal) spring stiffness } \\
\text { coefficient per unit area of the Kelvin model } \\
\left(\mathrm{N} / \mathrm{m} / \mathrm{m}^{2}\right)\end{array}$ & $\sigma_{l}^{+}$ & $\begin{array}{l}\text { initial circumferential stress in the liner per } \\
\text { unit length }(\mathrm{MN} / \mathrm{m}) \\
\text { perturbation of longitudinal stress in the liner }\end{array}$ \\
\hline$K_{w}$ & bulk modulus of water (MPa) & & per unit length $(\mathrm{MN} / \mathrm{m})$ \\
\hline$M_{r, l}$ & $\begin{array}{l}\text { radial (resp. longitudinal) additional mass per } \\
\text { unit area of the Kelvin model }\left(\mathrm{kg} / \mathrm{m}^{2}\right)\end{array}$ & $\sigma_{r}^{+}$ & $\begin{array}{l}\text { perturbation of circumferential stress in the } \\
\text { liner per unit length }(\mathrm{MN} / \mathrm{m})\end{array}$ \\
\hline$p$ & $\begin{array}{l}\text { water pressure in excess of the steady-state } \\
\text { pressure } p_{0} \text { used in the FSI case (MPa) }\end{array}$ & $\omega$ & $\begin{array}{l}\text { angular frequency of transient excitations } \\
(=2 \pi f)(\mathrm{rd} / \mathrm{s})\end{array}$ \\
\hline
\end{tabular}

and constraints and (b) to extend the use of the FSI model, derived by Kuiken (1984), to the field of steel-lined tunnels and shafts. Some examples with a sensitivity analysis of the main parameters are also provided in order to compare the results obtained in the frequency domain with the classical approaches. 


\section{Radial deformation of steel-lined pressure tunnels}

\subsection{Quasi-static case}

In general, the deformation of radial symmetrical multilayer systems is derived from compatibility conditions at the interfaces (Talobre, 1967; Schleiss, 1988). In the case of steel-lined pressure tunnels, three layer interfaces of radius $r_{c}, r_{a}$, and $r_{f}$, as shown in Fig. 1(a), exist. The compatibility of radial deformation $u_{r}$ at these three interfaces can be written as follows:

$$
\left\{\begin{array}{l}
u_{r}^{s}\left(r=r_{c}\right)-\Delta r_{0}=u_{r}^{c}\left(r=r_{c}\right) \quad \text { with } \quad \Delta r_{0} \geq 0 \\
u_{r}^{c}\left(r=r_{a}\right)=u_{r}^{\mathrm{crm}}\left(r=r_{a}\right), \\
u_{r}^{\mathrm{crm}}\left(r=r_{f}\right)=u_{r}^{\mathrm{rm}}\left(r=r_{f}\right)
\end{array}\right.
$$

where superscript $s$ is related to steel liner, $c$ to the backfill concrete, and crm and rm to the near- and far-field zones of the rock mass. The subscript $r$ indicates deformations in the radial direction. In contact with colder water, the steel liner shrinks and an initial gap $\Delta r_{0}$ may occur between steel and backfill concrete. A typical value of $\Delta r_{0}$ equal to $0.25 \%$ of $r_{i}$ is often used (Schleiss, 1988). In this paper, when the kinematic and dynamic effects of water and steel liner are considered (fluidstructure interaction phenomenon) under internal pressure, the steel liner is assumed to be in permanent contact with the backfill concrete and the gap can be thus ignored.

For any layer $j$, considered as a thick circular cylinder in axisymmetrical behaviour and with elasticity modulus $E_{j}$, interior radius $r_{j-1}$, and exterior radius $r_{j}$, the two general equations governing the deformation of this layer under internal $p_{j-1}$ and external pressures $p_{j}$ subject to uniform longitudinal strain $\varepsilon_{l}$, or uniform longitudinal stress $\sigma_{l}$, are (Halliwell, 1963; Timoshenko and Goodier, 1970)

$$
\begin{aligned}
& u_{r}^{j}(r)=\frac{1}{E_{j}} \frac{r_{j}^{2} r_{j-1}^{2}}{r_{j}^{2}-r_{j-1}^{2}}\left[\frac{\left(1+v_{j}\right)}{r}\left(p_{j-1}-p_{j}\right)+\left(1-v_{j}\right) r\left(\frac{p_{j-1}}{r_{j}^{2}}-\frac{p_{j}}{r_{j-1}^{2}}\right)\right]-\frac{v_{j} \sigma_{l} r}{E_{j}}, \\
& \varepsilon_{l}=\frac{\sigma_{l}}{E_{j}}-\frac{2 v_{j} r_{j}^{2} r_{j-1}^{2}}{E_{j}\left(r_{j}^{2}-r_{j-1}^{2}\right)}\left(\frac{p_{j-1}}{r_{j}^{2}}-\frac{p_{j}}{r_{j-1}^{2}}\right) .
\end{aligned}
$$

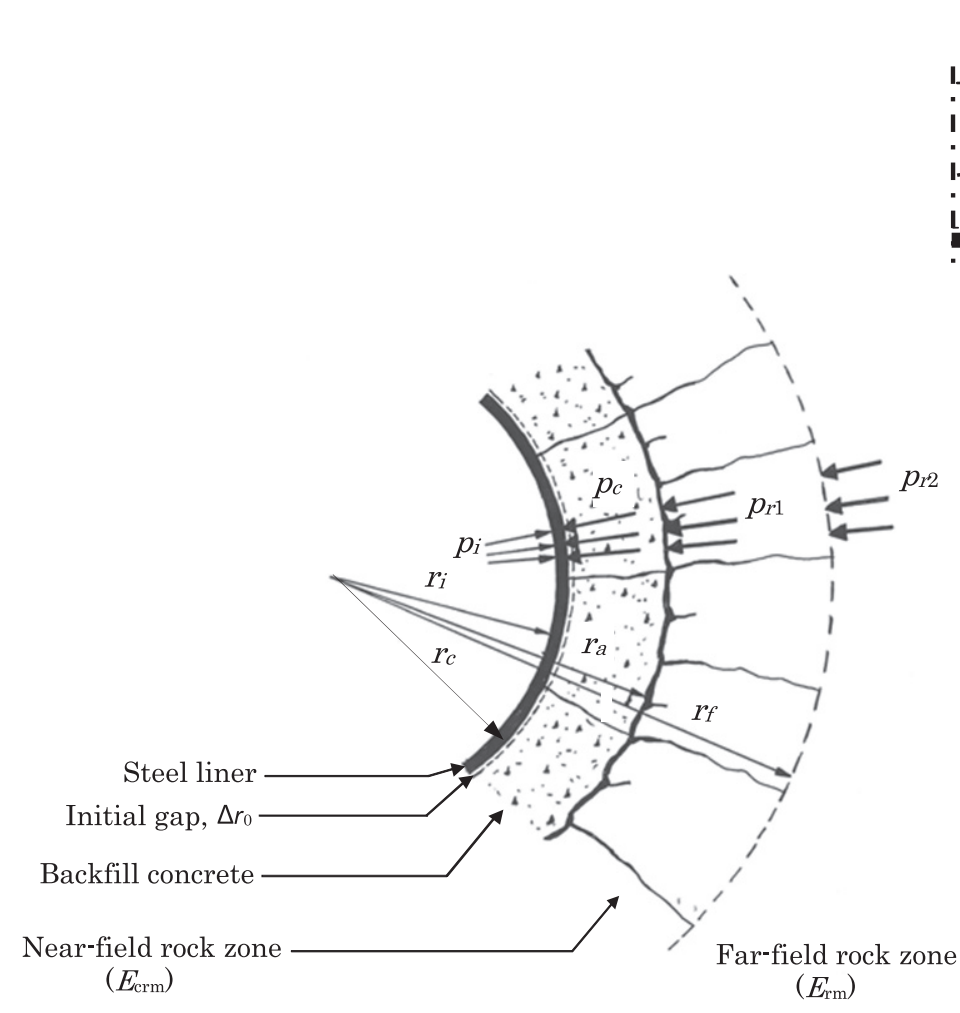

(a)
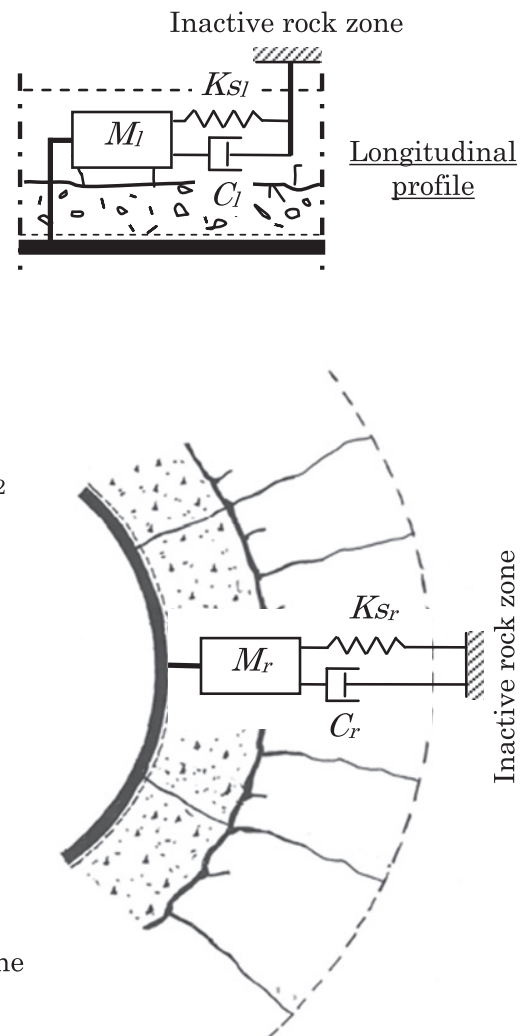

(b)

Fig. 1. Calculation models for steel liners with axisymmetrical behaviour: (a) used for the quasi-static wave speed calculation and (b) used for the frequencydependent wave speed calculation. 
In plane strain conditions $\left(\varepsilon_{l}=0\right)$, Eq. (2.3) becomes

$$
\sigma_{l}=\frac{2 v_{j} r_{j}^{2} r_{j-1}^{2}}{r_{j}^{2}-r_{j-1}^{2}}\left(\frac{p_{j-1}}{r_{j}^{2}}-\frac{p_{j}}{r_{j-1}^{2}}\right) \text {. }
$$

In the following discussion, uncracked materials or layers are homogenous, elastic with axisymmetrical behaviour, modelled according to thick-walled cylinder theory (Timoshenko and Goodier, 1970) while cracked layers cannot transfer tensile stresses (layers with radial cracks).

The displacements $u_{r}^{j}(r)$, of the different layers shown in the 2-D calculation model of Fig. 1(a), can be written as (Hachem and Schleiss, 2009)

(i) Steel liner

$$
u_{r}^{s}\left(r=r_{c}\right)=\frac{1+v_{s}}{E_{s}} \frac{r_{c}}{r_{c}^{2}-r_{i}^{2}}\left[\left(1-2 v_{s}\right)\left(p_{i} r_{i}^{2}-p_{c} r_{c}^{2}\right)+\left(p_{i}-p_{c}\right) r_{i}^{2}\right]
$$

(ii) Uncracked backfill concrete

$$
u_{r}^{c}\left(r=r_{a} \text { or } r_{c}\right)=\frac{1+v_{c}}{E_{c}} \frac{r}{r_{a}^{2}-r_{c}^{2}}\left[\left(1-2 v_{c}\right)\left(p_{c} r_{c}^{2}-p_{r 1} r_{a}^{2}\right)+\left(p_{c}-p_{r 1}\right) r^{2}\right] .
$$

(iii) Cracked backfill concrete

$$
u_{r}^{c}\left(r=r_{a}\right)=u_{r}^{c}\left(r=r_{c}\right)+\frac{\left(1-v_{c}^{2}\right) p_{c} r_{c}}{E_{c}} \ln \left(\frac{r_{c}}{r_{a}}\right),
$$

with, $\quad p_{c} r_{c}=p_{r 1} r_{a}$.

(iv) Uncracked near-field rock zone

In this case, the entire rock mass (near- and far-field) is treated as an infinite uncracked layer $\left(r_{f} \rightarrow \infty\right)$ ). The displacements $u_{r}^{\mathrm{rm}}$ at the interior face of the rock mass layer is

$$
u_{r}^{\mathrm{rm}}\left(r=r_{a}\right)=\frac{\left(1+v_{\mathrm{rm}}\right)}{E_{\mathrm{rm}}} p_{r 1} r_{a}
$$

(v) Cracked near-field rock zone

$$
u_{r}^{\mathrm{crm}}\left(r=r_{f}\right)=u_{r}^{\mathrm{crm}}\left(r=r_{a}\right)+\frac{\left(1-v_{\mathrm{rm}}^{2}\right) p_{r 1} r_{a}}{E_{\mathrm{crm}}} \ln \left(\frac{r_{a}}{r_{f}}\right)
$$

with, $\quad p_{r 1} r_{a}=p_{r 2} r_{f}$.

(vi) Uncracked infinite far-field rock zone when the near-field rock is considered as cracked

$$
u_{r}^{r m}\left(r=r_{f}\right)=\frac{\left(1+v_{r m}\right)}{E_{r m}} p_{r 2} r_{f}
$$

Note that Eq. (2.8) assuming cracked backfill concrete is derived from the theory of a thick-walled cylinder by putting the tensile stress $\sigma_{t}$ equal to zero in the general equation: $\sigma_{t}-\sigma_{r}-r \mathrm{~d} \sigma_{r} / \mathrm{d} r=0$ and then by integrating it between the two layers' borders where $\sigma_{r}=p_{c}$ at $r=r_{c}$ and $\sigma_{r}=p_{r 1}$ at $r=r_{a}$. Variables $\sigma_{t}$ and $\sigma_{r}$ stand, respectively, for the tensile and radial stresses in the cylinder wall and $\mathrm{d} \sigma_{r} / \mathrm{d} r$ for the first derivative of $\sigma_{r}$ relative to the radius $r$ measured from the tunnel axis. The same procedure is used to obtain Eq. (2.11) for cracked near-field rock zone. The far-field rock zone was assumed as homogeneous, isotropic and elastic with a mean elastic deformation modulus $E_{\mathrm{rm}}$.

The near-field rock zone corresponds to the rock mass disturbed (loosened) as a result of the excavation method and the change in the near stress field around the tunnel. Schleiss (1988) suggested values for the disturbed rock zone between 0.5-1.0 $\mathrm{m}$ for tunnels excavated by Tunnel Boring Machine (TBM) and 1.0-2.0 $\mathrm{m}$ for drill and blast excavation. In the paper, $r_{f}$ has been taken equal to 1.25 times $r_{a}$.

\subsection{General case considering kinematic and dynamic effects of water and steel liner}

Depending on the system stiffness of steel-lined pressure tunnels and penstocks, deviation from the quasi-static case may occur. Pressure waves in water produce dynamic forces on the steel liner and trigger vibrations. Such liner vibrations cause additional water pressure waves in return. This phenomenon is called "fluid-structure interaction" or "FSI". Compared to the 
conventional uncoupled water hammer analyses, FSI may lead to: higher or lower extreme dynamic pressures and steel wall stresses, change in the natural frequencies of the system, and more damping and dispersion in the pressure and stress histories (Kuiken, 1988). The dispersion results from a frequency-dependent wave speed built from different frequencies travelling at different speeds. This makes it difficult to identify the exact location of the wave front.

Denoting the axial displacement of the steel liner by $u_{l}^{s}$, the linearized boundary conditions at the water-liner interface using the no-slip condition are

$$
u=\frac{\partial u_{l}^{s}}{\partial t}, \quad v=\frac{\partial u_{r}^{s}}{\partial t}
$$

where $u$ and $v$ are, respectively, the water velocities in the axial $x$ and radial $r$ directions and $t$ is the time. The first boundary condition concerning the velocity $u$ is not needed in non-viscous fluid approximation (Rubinov and Keller, 1971).

The effect of the backfill concrete and the surrounding rock mass is mechanically modelled by a spring, a dashpot, and a lumped additional mass (Kelvin model). This conceptual model is represented in Fig. 1(b). The model input coefficients are $K s_{r}, C_{r}$, and $M_{r}$ representing, respectively, (per unit area) the spring stiffness coefficient, the frictional coefficient of the dashpot, and an additional mass. The same mechanical model is used to represent longitudinal liner-rock interaction with $K s_{l}$, $C_{l}$, and $M_{l}$ as coefficients.

The six-equation (3-mode) model of the FSI problem was established first by Atabeck (1968) and generalized by Kuiken (1984). These equations are:

(i) For the fluid without body forces in the axial $x$ and radial $r$ directions, the linearized equations of motions (Eqs. (2.14) and (2.15)), equation of continuity (Eq. (2.16)), and the thermodynamic constitutive equation for the density (Eq. (2.17)) are, respectively,

$$
\begin{aligned}
& \rho_{0} \frac{\partial u}{\partial t}=-\frac{\partial p}{\partial x}+\mu\left(\frac{\partial^{2} u}{\partial r^{2}}+\frac{1}{r} \frac{\partial u}{\partial r}+\frac{\partial^{2} u}{\partial x^{2}}\right)+\left(\kappa+\frac{1}{3} \mu\right)\left(\frac{\partial^{2} v}{\partial r \partial x}+\frac{1}{r} \frac{\partial v}{\partial x}+\frac{\partial^{2} u}{\partial x^{2}}\right), \\
& \rho_{0} \frac{\partial v}{\partial t}=-\frac{\partial p}{\partial r}+\mu\left(\frac{\partial^{2} v}{\partial r^{2}}+\frac{1}{r} \frac{\partial v}{\partial r}+\frac{\partial^{2} v}{\partial x^{2}}-\frac{v}{r^{2}}\right)+\left(\kappa+\frac{1}{3} \mu\right)\left(\frac{\partial^{2} v}{\partial r^{2}}+\frac{1}{r} \frac{\partial v}{\partial r}-\frac{v}{r^{2}}+\frac{\partial^{2} u}{\partial x \partial r}\right), \\
& \frac{\partial \rho}{\partial t}+\rho_{0}\left(\frac{\partial v}{\partial r}+\frac{v}{r}+\frac{\partial u}{\partial x}\right)=0, \\
& \mathrm{~d} p=c_{T}^{2} \mathrm{~d} \rho .
\end{aligned}
$$

(ii) For the steel liner, the equations of motion in an initially stressed field are (Flügge, 1973)

$$
\begin{aligned}
& \rho_{s} t_{s} \frac{\partial^{2} u_{l}^{s}}{\partial t^{2}}=\frac{\partial \sigma_{l}^{+}}{\partial x}+F_{x}+\sigma_{l}^{0} \frac{\partial^{2} u_{l}^{s}}{\partial x^{2}}-\frac{\sigma_{r}^{0}}{r_{i}} \frac{\partial u_{r}^{s}}{\partial x}, \\
& \rho_{s} t_{s} \frac{\partial^{2} u_{r}^{s}}{\partial t^{2}}=-\frac{\sigma_{r}^{+}}{r_{i}}+F_{r}+\sigma_{l}^{0} \frac{\partial^{2} u_{r}^{s}}{\partial x^{2}}+\frac{\sigma_{r}^{0}}{r_{i}} \frac{\partial u_{l}^{s}}{\partial x},
\end{aligned}
$$

where $\rho$ is the unit mass of water in excess of the steady-state unit mass $\rho_{0}, p$ is the water pressure in excess of the steadystate pressure $p_{0}, \mu$, and $\kappa$ are, respectively, the dynamic and the bulk viscosities of water, $\rho_{s}$ is the unit mass of steel, $t_{s}$ is the thickness of the liner, $\sigma_{r}^{+}$and $\sigma_{l}^{+}$are, respectively, the perturbation stresses in the circumferential and axial directions, $\sigma_{r}^{0}$ and $\sigma_{l}^{0}$ are the initial radial and longitudinal stresses in the liner evaluated per unit length, and $c_{T}$ is the speed of sound in unconfined water equal to $\left(K_{w} / \rho_{w}\right)^{0.5}$, where $K_{w}$ is the bulk modulus of water and $\rho_{w}$ is the unit mass of water when FSI is not considered. The forces $F_{x}$ and $F_{r}$ represent the resultant of hydrodynamic forces and forces applied by the surrounding backfill concrete on the liner, respectively, in the axial and radial directions. According to the Kelvin model, these forces are specified by

$$
\begin{aligned}
& F_{x}=-\mu\left[\frac{\partial u}{\partial r}+\frac{\partial v}{\partial r}\right]_{r=r_{i}}-M_{l} \frac{\partial^{2} u_{l}^{s}}{\partial t^{2}}-C_{l} \frac{\partial u_{l}^{s}}{\partial t}-K s_{l} u_{l}^{s}, \\
& F_{r}=\left[p-2 \mu \frac{\partial v}{\partial r}-\left(\kappa-\frac{2}{3} \mu\right)\left(\frac{1}{r} \frac{\partial r v}{\partial r}+\frac{\partial u}{\partial x}\right)\right]_{r=r_{i}}-M_{r} \frac{\partial^{2} u_{r}^{s}}{\partial t^{2}}-C_{r} \frac{\partial u_{r}^{s}}{\partial t}-K s_{r} u_{r}^{s} .
\end{aligned}
$$

Finally, the linear stress-strain relations for membranes are

$$
\sigma_{r}^{+}=B \frac{u_{r}^{s}}{r_{i}}+B_{(12)} \frac{\partial u_{l}^{s}}{\partial x}, \quad \sigma_{l}^{+}=B_{(12)} \frac{u_{r}^{s}}{r_{i}}+B \frac{\partial u_{l}^{s}}{\partial x},
$$

where $B$ and $B_{(12)}$ are defined in Eq. (2.30). 
The unknowns to be solved are $u, v, p, u_{l}^{s}$, and $u_{r}^{s}$. They are assumed to vary harmonically in $x$ and $t$ with a real constant angular frequency $\omega$ according to the following expressions in which the superscript ${ }^{\wedge}$ indicates the amplitude of the periodic quantities and $c$ denotes the complex propagation velocity

$$
[u, v, p]=[\hat{u}(r), \hat{v}(r), \hat{p}(r)] \mathrm{e}^{\mathrm{i} \omega(t-x / c)}, \quad\left[u_{l}^{s}, u_{r}^{s}\right]=\left[\hat{u}_{l}^{s}, \hat{u}_{r}^{s}\right] \mathrm{e}^{\mathrm{i} \omega(t-x / c)} .
$$

Any non-sinusoidal variable can be treated as the combination of an infinite number of harmonic components using Fourier transformation. In linear theory, small sinusoidal amplitude motions of the liner wall are considered.

By substituting Eq. (2.24) into Eqs. (2.14)-(2.16), and using Eq. (2.17), the following expressions for $\hat{u}(r), \hat{v}(r)$, and $\hat{p}(r)$ can be written

$$
\left\{\begin{array}{l}
\hat{u}(r)=\frac{\Phi_{1} \hat{p}_{0}}{\rho c_{0}}\left[k \mathrm{~J}_{0}\left(i \beta \zeta k r / r_{i}\right)+D \mathrm{~F}_{0}\left(\left(i^{3} \alpha^{2}-k^{2} \beta^{2}\right)^{0.5} \frac{r}{r_{i}}\right)\right], \\
\hat{v}(r)=\frac{\Phi_{1} \hat{p}_{0}}{\rho c_{0}}\left[\xi k \mathrm{~J}_{1}\left(i \beta \zeta k r / r_{i}\right)+0.5 \mathrm{i} \beta k D \mathrm{~F}_{1}\left(\left(i^{3} \alpha^{2}-k^{2} \beta^{2}\right)^{0.5} \frac{r}{r_{i}}\right)\right], \\
\hat{p}(r)=\hat{p}_{0} \mathrm{~J}_{0}\left(i \beta \zeta k r / r_{i}\right),
\end{array}\right.
$$

where $\hat{p}_{0}$ is the reference pressure amplitude of water at $r=0, i=(-1)^{0.5}, D$ an integration constant, and $c_{0}$ is the reference wave speed (defined in Eq. (4.2)), and the functions $\mathrm{F}_{n}\left(\lambda r / r_{i}\right)$ are defined by

$$
\mathrm{F}_{n}\left(\lambda r / r_{i}\right)=2^{n} n ! \frac{\mathrm{J}_{n}\left(\lambda r / r_{i}\right)}{\lambda^{n} \mathrm{~J}_{0}(\lambda)}
$$

$\mathrm{J}_{0}(y)$ and $\mathrm{J}_{1}(y)$ are, respectively, the zero- and first-order first-kind Bessel functions. In Eq. (2.26), the various dimensionless parameters are

$$
\left\{\begin{array}{l}
k=\frac{c_{0}}{c}, \quad \alpha=r_{i}\left(\frac{\omega \rho_{0}}{\mu}\right)^{0.5}, \quad \alpha^{\prime}=\alpha\left(\frac{\omega \rho_{0}}{\kappa}\right)^{0.5}, \quad \beta=\frac{\omega r_{i}}{c_{0}}, \quad \beta^{\prime}=\frac{\omega r_{i}}{c_{T}}, \\
\beta_{0 T}=\frac{c_{0}}{c_{T}}, \quad \zeta^{2}=1-\frac{\beta_{0 T}^{2}}{k^{2} \Phi_{1}}, \quad \Phi_{1}=1+\frac{\mathrm{i} \beta^{2}}{\alpha^{\prime 2}}+\frac{4 \mathrm{i} \beta^{2}}{3 \alpha^{2}} .
\end{array}\right.
$$

The first two homogeneous equations needed to solve the problem are derived from substitution of Eq. (2.26) into Eqs. (2.20) and (2.21). These latter equations with Eqs. (2.22) and (2.23) are then injected into Eqs. (2.18) and (2.19). The other two equations are derived from substitution of Eqs. (2.25) and (2.26) into the kinematic boundary condition (2.13). A nontrivial solution for the five unknowns plus the constant of integration $D$ is possible if the determinant is equal to zero. The following dispersion equation for an isotropic and elastic steel liner is thus obtained:

$$
\begin{aligned}
& k^{6}\left(\zeta^{2} F_{1 \beta}(1)-F_{1 \alpha}(1)\right) \beta^{2} B_{22}^{\prime} \sigma_{l}^{\prime 0}+k^{4}\left[\left(\zeta^{2} F_{1 \beta}(1)-F_{1 \alpha}(1)\right)\left(B_{22}^{\prime} B_{11}^{0}-B_{12}^{02}+K_{l}^{\prime} \sigma_{l}^{\prime 0}\right)-0.5 \zeta^{2} F_{1 \beta}(1) F_{1 \alpha}(1) \beta^{2} \sigma_{l}^{\prime 0}\right] \\
& \quad+k^{2}\left[F_{1 \alpha}(1)\left(B_{12}^{0}+\Phi_{4} B_{21}^{0}-0.5 B_{11}^{0} \zeta^{2} F_{1 \beta}(1)\right)-2 \Phi_{4} B_{22}^{\prime}+\left(K_{l}^{\prime} / \beta^{2}\right) B_{11}^{0}\left(\zeta^{2} F_{1 \beta}(1)-F_{1 \alpha}(1)\right)\right]+\Phi_{4}\left[F_{1 \alpha}(1)-2\left(K_{l}^{\prime} / \beta^{2}\right)\right]=0,
\end{aligned}
$$

where

$$
\left\{\begin{array}{l}
B_{22}^{\prime}=\frac{B+\sigma_{l}^{0}}{\rho r_{i} c_{0}^{2}}, \quad B=\frac{E_{s} t_{s}}{\left(1-v_{s}^{2}\right)}, \quad \sigma_{l}^{\prime 0}=\frac{\sigma_{l}^{0}}{\rho r_{i} c_{0}^{2}}, \\
B_{11}^{0}=B_{11}^{\prime}+K_{r}^{\prime}-\frac{2 \mathrm{i} \beta^{2}}{\alpha}, \quad B_{11}^{\prime}=\frac{B}{\rho r_{i} c_{0}^{2}}, \\
K_{r, l}=\frac{r_{i}}{\rho c_{0}^{2}}\left[K s_{r, l}+\mathrm{i} \omega C_{r, l}-\omega^{2}\left(M_{r, l}+\rho_{s} t_{s}\right)\right], \quad B_{21}^{0}=B_{12}^{0}=B_{12}^{\prime}-\frac{2 \mathrm{i} \beta^{2}}{\alpha^{2}}, \\
B_{12}^{\prime}=\frac{B_{(12)}-\sigma_{r}^{0}}{\rho r_{i} c_{0}^{2}}, \quad B_{(12)}=\frac{E_{s} t_{s} v_{s}}{\left(1-v_{s}^{2}\right)}, \quad \Phi_{4}=\frac{\Phi_{2}+\left(2 \mathrm{i} \beta^{\prime 2} / \alpha^{2}\right)}{\Phi_{1}}, \quad \Phi_{2}=1-\frac{\mathrm{i} \beta^{2}}{\alpha^{2}}+\frac{2 \mathrm{i} \beta^{\prime 2}}{3 \alpha^{2}},
\end{array}\right.
$$

and $F_{1 \alpha}\left(\frac{r}{r_{i}}\right)$ and $F_{1 \beta}\left(\frac{r}{r_{i}}\right)$ stand, respectively, for the first members of

$$
\left\{\begin{array}{l}
F_{n \alpha}\left(\frac{r}{r_{i}}\right) \equiv \mathrm{F}_{n}\left(\left(\mathrm{i}^{3} \alpha^{2}-k^{2} \beta^{2}\right)^{0.5} \frac{r}{r_{i}}\right) ; \quad n=0,1 \\
F_{n \beta}\left(\frac{r}{r_{i}}\right) \equiv \mathrm{F}_{n}\left(\mathrm{i} \beta \zeta k \frac{r}{r_{i}}\right) ; \quad n=0,1 .
\end{array}\right.
$$

The complete solution is finally obtained for a linear combination of the forward and backward propagation mode for infinitely long tunnels and shafts. Using Eqs. (2.26), the linear combination of the solution (2.24) for each mode gives

$$
\left\{\begin{array}{l}
u(r)=\frac{\Phi_{1} \hat{p}\left(r_{i}\right)}{\rho c_{0}} k\left[F_{0 \beta}\left(\frac{r}{r_{i}}\right)+D^{\prime} F_{0 \alpha}\left(\frac{r}{r_{i}}\right)\right]\left[D_{1} \cos \left(\frac{\omega x}{c}\right)+D_{2} \sin \left(\frac{\omega x}{c}\right)\right] \mathrm{e}^{\mathrm{i} \omega t}, \\
v(r)=\frac{\Phi_{1} \hat{p}\left(r_{i}\right)}{\rho c_{0}} 0.5 \beta k^{2}\left[\zeta^{2} F_{1 \beta}\left(\frac{r}{r_{i}}\right)-D^{\prime} F_{1 \alpha}\left(\frac{r}{r_{i}}\right)\right]\left[-D_{1} \sin \left(\frac{\omega x}{c}\right)+D_{2} \cos \left(\frac{\omega x}{c}\right)\right] \mathrm{e}^{\mathrm{i} \omega t}, \\
p(r)=\hat{p}\left(r_{i}\right) F_{0 \beta}\left(\frac{r}{r_{i}}\right)\left[-D_{1} \sin \left(\frac{\omega \cdot x}{c}\right)+D_{2} \cos \left(\frac{\omega x}{c}\right)\right] \mathrm{e}^{\mathrm{i} \omega t},
\end{array}\right.
$$


where the complex constants $D_{1}$ and $D_{2}$ are determined, for each mode, by boundary conditions at two different sections of the steel-lined tunnel, and the mode-dependent factor $D^{\prime}$ is defined by

$$
D^{\prime}=-\frac{D}{k j_{0}(i \beta \zeta k)}=\frac{\left[\left(B_{11}^{0}+k^{2} \beta^{2} \sigma_{l}^{0}\right) \zeta^{2} F_{1 \beta}-2 B_{12}^{0}\right] k^{2}-2 \Phi_{4}}{\left[\left(B_{11}^{0}+k^{2} \beta^{2} \sigma_{l}^{\prime 0}\right) F_{1 \alpha}-2 B_{12}^{0}\right] k^{2}} .
$$

The radial and longitudinal displacements of the steel liner or penstock wall result from the summation of the mode solutions. For each mode, the solution is

$$
\left\{\begin{array}{l}
u_{r}^{s}(x, t)=0.5 r_{i} k^{2}\left(\zeta^{2} F_{1 \beta}(1)-D^{\prime} F_{1 \alpha}(1)\right)\left(\frac{\Phi_{1} p\left(r_{i}\right)}{\rho c_{0}^{2}}\right) \\
u_{l}^{s}(x, t)=-\mathrm{i} r_{i} \frac{k}{\beta}\left(1-D^{\prime}\right)\left(\frac{\Phi_{1} p\left(r_{i}\right)}{\rho \cdot c_{0}^{2}}\right)
\end{array}\right.
$$

\section{Water-hammer wave-speed expressions without fluid-structure interaction}

\subsection{General expressions for wave speed estimation}

The classical theory of water hammer predicts pressure wave propagation inside a frictionless closed cylinder with uniform cross section at a wave speed given by the following general formula (Wylie et al., 1993)

$$
a=\sqrt{\frac{1}{\rho_{w}\left(1 / K_{w}+(1 / A)\left(\mathrm{d} A / \mathrm{d} p_{i}\right)\right)}},
$$

where $\mathrm{d} A$ is the variation of the cross-sectional area $A$ of the cylinder caused by the variation of the internal water pressure $\mathrm{d} p_{i}$.

For multiphase (vapour cavities are present) and multicomponent (suspended sediment is present) flow, the bulk modulus $K_{w}$ and the unit mass $\rho_{w}$ are substituted in Eq. (3.1) with an effective bulk modulus $K_{e}$ and an effective unit mass $\rho_{e}$ (Wylie et al., 1993).

Without considering the FSI and by ignoring the dynamic effect of the tunnel wall, $\mathrm{d} A / \mathrm{d} p_{i}$ is a constant value. This results in a constant, or quasi-static, wave speed.

In plain strain conditions and considering the hypothesis of linear elasticity and small deformations with $r_{i} \approx r_{c}$ (thinwalled liners are considered), Eq. (3.1) can be written according to Fig. 1(a) as follows:

$$
a=\sqrt{\frac{1}{\rho_{w}\left(\left(1 / K_{w}\right)+\left(2 / r_{i}\right)\left(\mathrm{d} u_{r}^{s}\left(r_{i}\right) / \mathrm{d} p_{i}\right)\right)}}
$$

in which $\mathrm{d} u_{r}^{s}\left(r_{i}\right) / \mathrm{d} p_{i}$ is the first derivative of $u_{r}^{s}$ relative to the internal pressure $p_{i}$ at the layer interface of radius $r_{i}$.

\subsubsection{Case 1: Backfill concrete and near-rock mass zone are uncracked}

For this case, the transmitted load to the rock is first determined as a function of $p_{i}, \Delta r_{0}$, and the materials characteristics by solving the system of the compatibility of deformation (2.1) using Eqs. (2.5), (2.6) and (2.9). The radial deformation of the steel liner, $u_{r}^{s}\left(r_{c}\right)$ and its derivative according to $p_{i}$ are then computed from Eq. (2.5).

The complete expression of water-hammer wave speed is obtained by replacing the following expression of $\mathrm{d} u_{r}^{s}\left(r_{c}\right) / \mathrm{d} p_{i}$ in Eq. (3.2)):

$$
\frac{\mathrm{d} u_{r}^{s}\left(r_{c}\right)}{\mathrm{d} p_{i}}=\frac{2\left(1+v_{c}\right)\left(1-v_{s}^{2}\right) r_{c} r_{i}^{2}\left[E_{c}\left(1+v_{\mathrm{rm}}\right)\left(\left(1-2 v_{c}\right) r_{c}^{2}+r_{a}^{2}\right)-E_{\mathrm{rm}}\left(1+v_{c}\right)\left(1-2 v_{c}\right)\left(r_{c}^{2}-r_{a}^{2}\right)\right]}{A_{1}+A_{2}},
$$

where

$$
\begin{aligned}
& \mathrm{A}_{1}=E_{s}\left(r_{c}^{2}-r_{i}^{2}\right)\left(E_{\mathrm{rm}}\left(1+v_{s}\right)^{2}\left(2 v_{c}-1\right)\left(r_{c}^{2}-r_{a}^{2}\right)-E_{c}\left(1+v_{c}\right)\left(1+v_{\mathrm{rm}}\right)\left(\left(2 v_{c}-1\right) r_{c}^{2}-r_{i}^{2}\right)\right), \\
& A_{2}=E_{c}\left(1+v_{s}\right)\left(\left(2 v_{s}-1\right) r_{c}^{2}-r_{i}^{2}\right)\left(\left(1+v_{\mathrm{rm}}\right)\left(r_{c}^{2}-r_{a}^{2}\right)-E_{\mathrm{rm}}\left(1+v_{c}\right)\left(r_{c}^{2}-\left(2 v_{c}-1\right) r_{a}^{2}\right)\right) .
\end{aligned}
$$

3.1.2. Case 2: Backfill concrete is cracked while rock mass is not

Eqs. (2.5), (2.7), (2.8) and (2.9) are used to solve the system of Eqs. (2.1) for $p_{c}, p_{r 1}$, and $u_{r}^{s}\left(r_{c}\right)$. The following expression of $\mathrm{d} u_{r}^{s}\left(r_{c}\right) / \mathrm{d} p_{i}$ is then replaced in Eq. (3.2):

$$
\frac{\mathrm{d} u_{r}^{s}\left(r_{c}\right)}{\mathrm{d} p_{i}}=\frac{2\left(v_{s}^{2}-1\right) r_{c} r_{i}^{2}\left[E_{c}\left(1+v_{\mathrm{rm}}\right)-\left(1-v_{c}^{2}\right) E_{\mathrm{rm}} \ln \left(\frac{r_{c}}{r_{a}}\right)\right]}{A_{3}+A_{4}}
$$

where

$$
\left\{\begin{array}{l}
A_{3}=E_{c}\left[E_{\mathrm{rm}}\left(1+v_{s}\right)\left(\left(2 v_{s}-1\right) r_{c}^{2}-r_{i}^{2}\right)-E_{s}\left(1+v_{\mathrm{rm}}\right)\left(r_{c}^{2}-r_{i}^{2}\right)\right], \\
A_{4}=\left(1-v_{c}^{2}\right) E_{\mathrm{rm}} E_{s}\left(r_{c}^{2}-r_{i}^{2}\right) \ln \left(\frac{r_{c}}{r_{a}}\right) .
\end{array}\right.
$$


3.1.3. Case 3: Backfill concrete and near-rock zone are cracked

For this case, the expression of $\mathrm{d} u_{r}^{s}\left(r_{c}\right) / \mathrm{d} p_{i}$ is obtained by replacing $E_{c}$ by $\left(E_{c} E_{\mathrm{crm}}\right)$ and $\left(1-v_{c}^{2}\right) \ln \left(r_{c} / r_{a}\right)$ by $\left[\left(1-v_{c}^{2}\right) E_{\mathrm{crm}} \ln \left(r_{\mathrm{c}} / r_{a}\right)+\right.$ $\left.\left(1-v_{\mathrm{rm}}^{2}\right) E_{c} \ln \left(r_{\mathrm{a}} / r_{f}\right)\right]$ in Eq. (3.4). This yields to the following expression:

$$
\frac{\mathrm{d} u_{r}^{s}\left(r_{c}\right)}{\mathrm{d} p_{i}}=\frac{2\left(v_{s}^{2}-1\right) r_{c} r_{i}^{2}\left[E_{c} E_{c r m}\left(1+v_{\mathrm{rm}}\right)-E_{\mathrm{rm}}\left(\left(1-v_{c}^{2}\right) E_{\mathrm{crm}} \ln \left(\frac{r_{c}}{r_{a}}\right)+\left(1-v_{r m}^{2}\right) E_{c} \ln \left(\frac{r_{a}}{r_{f}}\right)\right)\right]}{A_{5}+A_{6}},
$$

where

$$
\begin{aligned}
& A_{5}=E_{c} E_{c r m}\left[E_{\mathrm{rm}}\left(1+v_{s}\right)\left(\left(2 v_{s}-1\right) r_{c}^{2}-r_{i}^{2}\right)-E_{s}\left(1+v_{\mathrm{rm}}\right)\left(r_{c}^{2}-r_{i}^{2}\right)\right], \\
& A_{6}=E_{\mathrm{rm}} E_{s}\left(r_{c}^{2}-r_{i}^{2}\right)\left(\left(1-v_{c}^{2}\right) E_{\mathrm{crm}} \ln \left(\frac{r_{c}}{r_{a}}\right)+\left(1-v_{r m}^{2}\right) E_{\mathrm{c}} \ln \left(\frac{r_{a}}{r_{f}}\right)\right) .
\end{aligned}
$$

This case of the calculation scheme can be considered as the most realistic case. In fact, the backfill concrete with low tensile strength is normally cracked, and the close rock field is disturbed and cracked as a result of excavation and the change in the stress field around the tunnel. Only radial compressive stresses can be transmitted in these cracked zones. The waterwave-velocity expression for this case is referred in this paper as the "complete quasi-static expression" which is valid for wave-speed calculation in frictionless circular steel-lined tunnel with axisymmetrical behaviour. The complete quasi-static expression neglects fluid-structure interaction.

\subsection{Comparison of calculated wave speeds for Cases 1,2 , and 3}

For comparison of Cases 1, 2 and 3, three configurations with different elasticity modulus for the far-field rock zone $\left(E_{\mathrm{rm}}=5 \%, 10 \%\right.$, and $20 \%$ of $\left.E_{s}\right)$ were analyzed by using the following input values:

$$
\begin{aligned}
& E_{s}=210000 \mathrm{MPa} ; \quad E_{c}=21000 \mathrm{MPa} ; \quad E_{c r m}=0.5 E_{r m} \\
& v_{s}=0.30 ; \quad v_{c}=0.20 ; \quad v_{r m}=0.25 \\
& r_{a}=1.2 r_{i} ; \quad r_{f}=1.25 r_{a} ; \quad K_{w}=2200 \mathrm{MPa} ; \quad \rho_{w}=1000 \mathrm{~kg} / \mathrm{m}^{3}
\end{aligned}
$$

In Fig. 2, the quasi-static wave speeds for the three cases are given. The relative differences of Cases 1 and 2 compared to Case 3 are indicated as a function of $\left(r_{i} / t_{s}\right)$ for the three $\left(E_{\mathrm{rm}} / E_{s}\right)$ ratios. If the near-rock mass zone is considered as uncracked with cracked backfill concrete (Case 2), it can be seen that the wave speed is higher, compared to the cracked layers case (Case 3). This augmentation of wave speed is $1-1.5 \%$ for thick steel liners and $1.5-4 \%$ for thin steel liners. If the backfill concrete and the near-rock field are both considered as uncracked (Case 1), the overestimation of the wave speed, compared to Case 3 , is between $2 \%$ and $8 \%$ for thin steel liners. For thick liners, the overestimation is between $1 \%$ and $2.5 \%$. The highest differences in the computed values of the wave speed are observed for relatively weak rock-mass moduli.

\subsection{Comparison with other simplified expressions}

\subsubsection{Jaeger's formula}

Jaeger $(1972,1977)$ published the following formula to estimate the pressure wave velocity in steel-lined pressure tunnels:

$$
a=\sqrt{\frac{1}{\rho_{w}\left(\left(1 / K_{w}\right)+\left(2 r_{c}\left(1-\lambda_{1}\right) / E_{s}\left(r_{c}-r_{i}\right)\right)\right)}},
$$

where

$$
\lambda_{1}=\frac{r_{c}^{2} / E_{s} t_{s}}{\left(r_{c}^{2} / E_{s} t_{s}\right)+\left(r_{a}^{2}-r_{c}^{2} / 2 E_{c} r_{a}\right)+\left(v_{\mathrm{rm}}\left(1+1 / v_{\mathrm{rm}}\right) r_{c} / E_{\mathrm{rm}}\right)} .
$$

This formula was derived from the same hypotheses as the Case 2 model. The steel liner is treated as a thin circular cylinder and the mean radial deformation of the backfill concrete is taken into account. However, the steel and concrete Poisson ratios are ignored.

The quasi-static wave speeds calculated according to Jaeger's formula for different $\left(E_{\mathrm{rm}} / E_{s}\right)$ ratios and their relative differences compared to Case 3 are shown in Fig. 3(a). Jaeger's relation overestimates the water hammer velocity relative to the complete quasi-static expression. The maximum relative difference reaches $3.5 \%$ for $r_{i} / t_{s} \approx 130$ and $E_{\mathrm{rm}} / E_{s}=0.05$.

\subsubsection{Parmakian's formula}

Parmakian (1963) proposed a formula considering a steel liner surrounded by uncracked and infinite rock mass. The influence of the backfill concrete and the steel Poisson ratio are ignored. The same relation has also been used by 

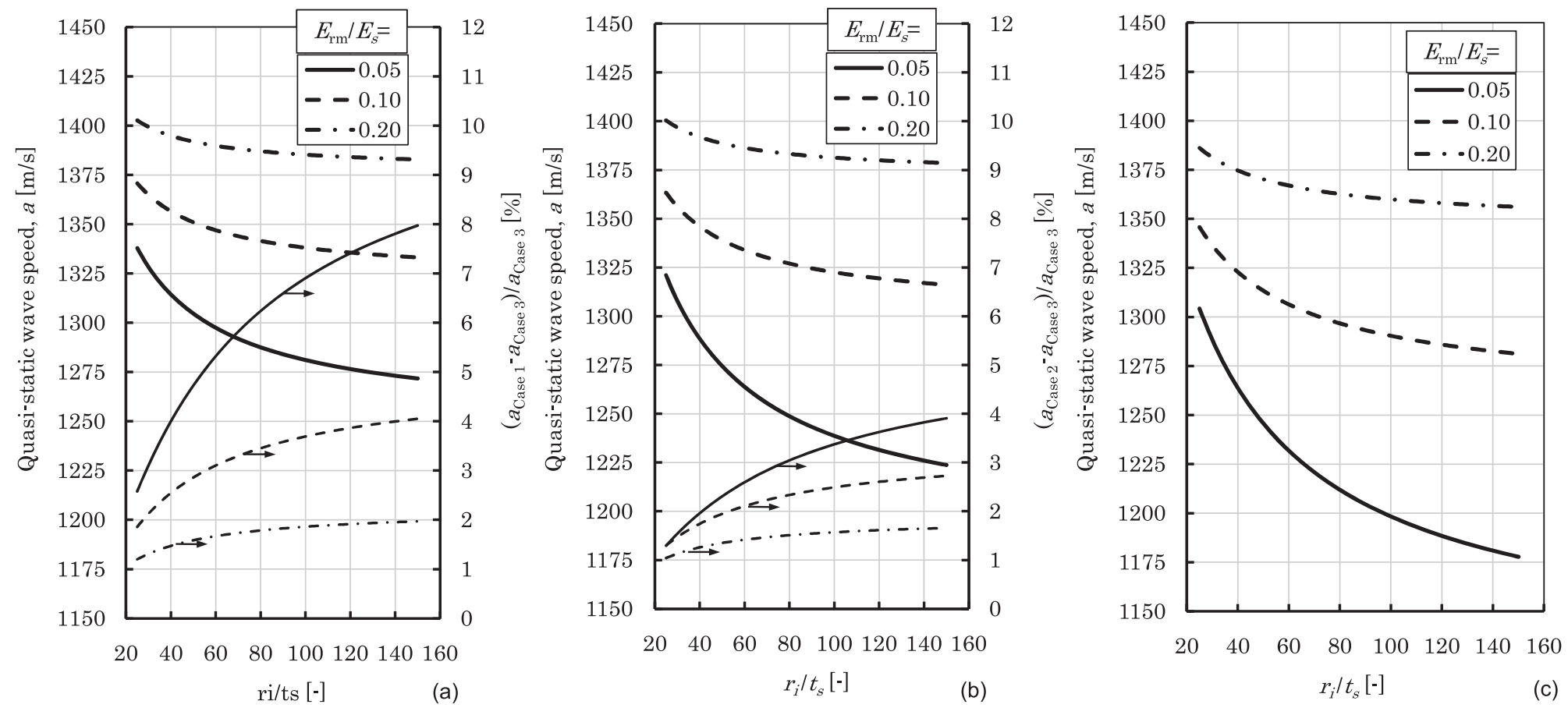

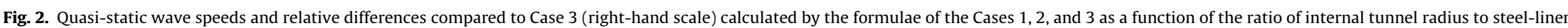

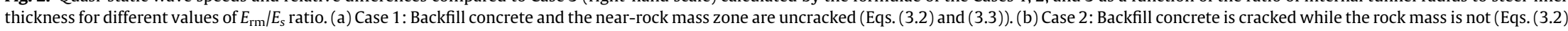
and (3.4)). (c) Case 3: Backfill concrete and the near-rock zone are cracked (Eqs. (3.2) and (3.5)). 

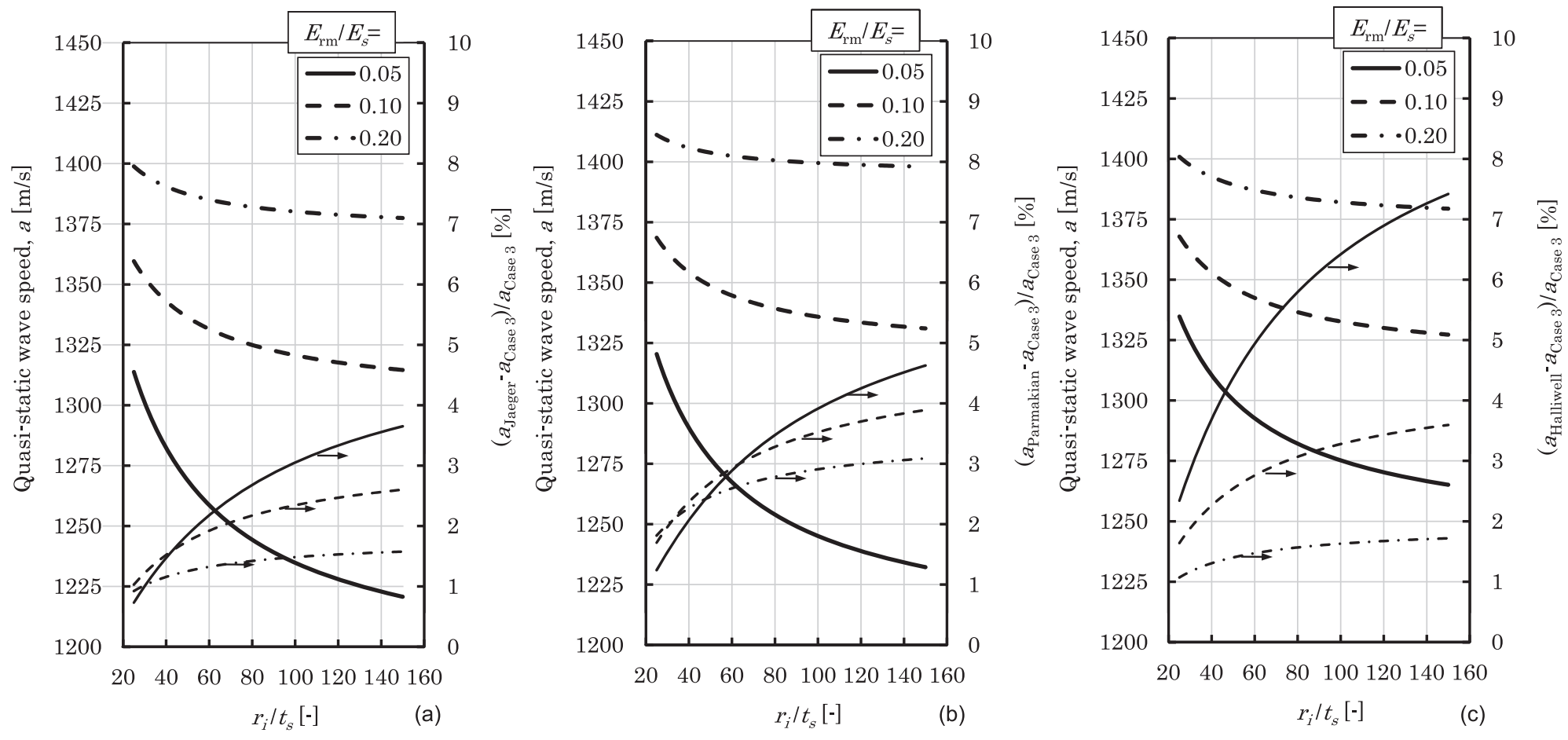

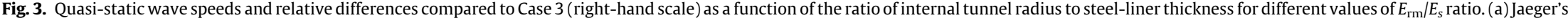
formula (Eqs. (3.6) and (3.7)). (b) Parmakian's formula (Eq. (3.8)). (c) Halliwell's formula (Eqs. (3.9) and (3.10)). 
Chaudhry (1987). It is given as follows:

$$
a=\sqrt{\frac{1}{\rho_{w}\left(\left(1 / K_{w}\right)+\left(2 r_{i}\left(1+v_{\mathrm{rm}}\right) / E_{r m} r_{i}+E_{s} t_{s}\left(1+v_{\mathrm{rm}}\right)\right)\right)}} .
$$

Fig. 3(b) shows that the wave speed values computed by Parmakian's relation are higher than values obtained from the complete quasi-static expression. For $E_{\mathrm{rm}} / E_{s}=0.05$, the wave speed is overestimated by $3-4.6 \%$ for $r_{i} / t_{s} \approx 150$.

\subsubsection{Halliwell's formula}

Halliwell (1963) derived a formula for the wave speed assuming an uncracked concrete and rock mass surrounding the steel liner. The same Poisson ratios for steel, concrete, and rock are considered. Salah et al. (2001) generalized Halliwell's formula using different Poisson ratios for each material.

Halliwell's wave speed equation is written as follows:

$$
a=\sqrt{\frac{1}{\rho_{w}\left(\left(1 / K_{w}\right)+\left(2 r_{c}\left(1-v^{2}\right)\left(1-\lambda_{2}\right) / E_{s}\left(r_{c}-r_{i}\right)\right)\right)}},
$$

where

$$
\lambda_{2}=\frac{(1-v) r_{c}}{(1-v) r_{c}+\frac{E_{S}\left(r_{c}-r_{i}\right)}{E_{c}} \frac{E_{c}\left(r_{a}^{2}+r_{c}^{2}(1-2 v)\right)+E_{\mathrm{rm}}(1-2 v)\left(r_{a}^{2}-r_{c}^{2}\right)}{E_{c}\left(r_{a}^{2}-r_{c}^{2}\right)+E_{\mathrm{rm}}\left(r_{c}^{2}+r_{a}^{2}(1-2 v)\right)},}
$$

and $v_{\mathrm{s}}=v_{\mathrm{c}}=v_{\mathrm{rm}}=v$.

The wave speed and relative differences computed from Halliwell's formula are shown in Fig. 3(c). This formula gives wave speed values of approximately $7.5 \%$ higher than the complete quasi-static expression for $r_{i} / t_{s}=150$ and $E_{\mathrm{rm}} / E_{s}=0.05$ assuming $v=0.3$.

\subsubsection{Special case of open-air penstocks and unlined pressure tunnels}

(a) Open-air penstocks

The pressure wave speed relation for a longitudinally blocked penstock can be derived from Eq. (3.3) of Case 1 by putting $r_{a}=r_{c}$ and by replacing $v_{c}, v_{\mathrm{rm}}, E_{c}$, and $E_{\mathrm{rm}}$ by zeros and $\left(r_{c}+r_{i}\right)$ by $2 r_{i}$. Considering the longitudinal boundary conditions of the penstock, Halliwell (1963) generalized the formula and Streeter (1963) corrected it in the case of penstocks that can freely slip in the longitudinal direction as follows:

$$
a=\sqrt{\frac{1}{\rho_{w}\left(\left(1 / K_{w}\right)+\left(2 r_{i} \lambda_{3} / E_{s} t_{s}\right)\right)}},
$$

where

$$
\lambda_{3}=\left[\begin{array}{ll}
1-0.5 v_{s} & \text { if the penstock can freely slip in the longitudinal direction, } \\
1 & \text { if the penstock has expansion joints over its entire length, } \\
1-v_{s}^{2} & \text { if the penstock is blocked in the longitudinal direction. }
\end{array}\right.
$$

(b) Unlined pressure tunnels

The wave speed in an unlined pressure tunnel can be deduced from Case 1 by putting $r_{a}=r_{c}=r_{i}$ and by setting $v_{s}, v_{c}, E_{s}$, and $E_{c}$ equal to zero. Then, the wave speed can be written as

$$
a=\sqrt{\frac{1}{\rho_{w}\left(\left(1 / K_{w}\right)+\left(2\left(1+v_{\mathrm{rm}}\right) / E_{\mathrm{rm}}\right)\right)}} .
$$

The same relation has been proposed by Parmakian (1963) while in Jaeger (1977), $v_{\mathrm{rm}}$ has also been set equal to zero. Jaeger's approximation leads to a wave speed overestimation of $3.5 \%$ for $E_{\mathrm{rm}}=10000 \mathrm{MPa}$ and $v_{\mathrm{rm}}=0.25$.

\subsection{Definition of an apparent rock mass modulus}

The purpose of the definition of such apparent rock mass modulus is to simplify the complicated expression of the quasistatic wave speed of the complete quasi-static expression (Case 3). The backfill concrete and the near-and far-rock masses are replaced by an equivalent homogeneous rock mass with an apparent elasticity modulus, $E_{\text {app }}$.This latter is defined such that the transmitting load ratio from steel to the equivalent rock mass is the same as in Case 3. The apparent rock mass modulus can be obtained by equating the wave velocity expressions in Cases 1 or 2 (with $r_{a} \rightarrow r_{c}$ and $E_{\mathrm{rm}}$ replaced by $E_{\mathrm{app}}$ ) with wave 
velocity in Case 3 (with $r_{a} \rightarrow r_{c}$ )

$a($ Case 1 or 2$)=a($ Case 3$)$.

Eq. (3.13) leads to two expressions defining respectively $E_{\text {app }}$ and $a$ as follows:

$$
\begin{aligned}
& E_{\mathrm{app}}=\frac{E_{\mathrm{rm}} E_{\mathrm{crm}}}{E_{\mathrm{crm}}-E_{\mathrm{rm}}\left(1-v_{r m}\right) \ln \left(r_{c} / r_{f}\right)}, \\
& a=\sqrt{\frac{1}{\rho_{W}\left[\frac{1}{K_{W}}+\frac{4\left(v_{s}^{2}-1\right)\left(1+v_{\mathrm{rm}}\right) r_{c} r_{i}}{E_{\mathrm{app}}\left(1+v_{s}\right)\left[\left(2 v_{s}-1\right) r_{c}^{2}-r_{i}^{2}\right]-E_{s}\left(1+v_{\mathrm{rm}}\right)\left(r_{c}^{2}-r_{i}^{2}\right)}\right]}} .
\end{aligned}
$$

\section{Water-hammer wave-speed expressions considering the fluid-structure interaction}

\subsection{General expressions}

By considering the water as a compressible non-viscous fluid $(\mu=\kappa=0)$ and by neglecting the initial longitudinal stress in the steel liner $\left(\sigma_{l}^{0}=0\right)$, the dispersion Eq. (2.29) can be simplified as follows:

$$
\left[\left(B_{22}^{\prime}+K_{r}^{\prime}\right) K_{l}^{\prime}+k^{2} \beta^{2}\left(B_{22}^{\prime 2}+B_{22}^{\prime} K_{r}^{\prime}-B_{12}^{\prime 2}\right)\right]\left(k^{2} \beta^{2}-\beta^{\prime 2}\right) F_{1}\left(i\left(k^{2} \beta^{2}-\beta^{\prime 2}\right)^{0.5}\right)=2 \beta^{2}\left(K_{l}^{\prime}+k^{2} B_{22}^{\prime} \beta^{2}\right) .
$$

The reference velocity $c_{0}$ can be written, according to Kuiken (1984), as

$$
c_{0}=\sqrt{\frac{1}{\rho_{w}\left(\left(1 / K_{w}\right)+C\left(2 r_{i} / E_{s} t_{s}\right)\right)}},
$$

where

$$
C=\frac{1-v_{s}^{2}}{1+\left(K_{r} / B\right)}
$$

and

$$
K_{r}=r_{i}^{2}\left[K s_{r}+\mathrm{i} \omega C_{r}-\omega^{2}\left(M_{r}+\rho_{s} t_{s}\right)\right]
$$

$\omega$ is the real angular frequency $(=2 \pi f)$ of the continuous excitation of frequency $f$.

If $K s_{r}$ is taken equal to $\left(p_{c} / u_{r}^{s}\left(r_{c}\right)\right)$, calculated according to Case 3, and if $\omega$ is very small, $c_{0}$ is equal to the complete quasistatic wave speed. When $\omega$ approaches infinity, $c_{0}$ becomes the speed of sound in unconfined water $\left(K_{w} / \rho_{w}\right)^{0.5}$.

The solutions of the quadratic dispersion Eq. (4.1) occur in pairs $( \pm k)$ where each $\pm k$ solution is associated to a particular mode of oscillation with waves propagating in positive and negative directions along $x$. The modes with small values of the imaginary part of $k$ are the propagating modes, whereas the modes with high values of the imaginary part of $k$ decay rapidly according to the following expression:

$$
[u, v, p]=\left[\hat{u}(r), \hat{v}(r), \hat{p}_{i}(r)\right] \mathrm{e}^{\mathrm{i} \omega(t-x / c)}=\left[\hat{u}(r), \hat{v}(r), \hat{p}_{i}(r)\right] \mathrm{e}^{-\Delta_{i} x / \lambda_{i}} \mathrm{e}^{\mathrm{i} \omega\left(t-x / c_{i}\right)},
$$

where $\lambda_{i}$ is the wave length of the $i$ th wave mode, $c_{i}$ is the phase velocity, $c_{p i}$ or the group velocity, $c_{g i}$, and $\Delta_{i}$ is the logarithmic decrement of the $i$ th wave mode. The phase velocity of a travelling wave form may or may not correspond to a particular physical entity and does not necessarily correspond to the speed at which energy or information is propagating. That is why the phase velocity might go to infinity and be higher than the speed of sound in unconfined water. Hence, the energy of the wave propagates with the group velocity when this later is smaller than the phase velocity. The parameters of Eq. (4.5) with the equivalent reference wave speed are defined by

$$
\lambda_{i}=2 \pi \frac{c_{i}}{\omega}
$$

Phase velocity, $\quad c_{p i}=\frac{1}{\operatorname{Re}\left[k / c_{0}\right]}, \quad$ Group velocity, $\quad c_{g i}=\frac{\mathrm{d} \omega}{d\left(\omega \operatorname{Re}\left[k / c_{0}\right]\right)}$,

$$
\Delta_{i}=-2 \pi \frac{\operatorname{Im}\left[k / c_{0}\right]}{\operatorname{Re}\left[k / c_{0}\right]}, \quad c_{0 \text { eq }}=\frac{\operatorname{Re}\left[c_{0}\right]^{2}+\operatorname{Im}\left[c_{0}\right]^{2}}{\operatorname{Re}\left[c_{0}\right]},
$$

where $\operatorname{Re}[$ ] and $\operatorname{Im}[$ ] are, respectively, the real and imaginary parts of the complex numbers.

Rubinov and Keller $(1971,1978)$ showed that, for the non-viscous fluid approximation, two modes (called tube modes) can only propagate at low frequencies (with or without cut-off bands) and an infinite number of acoustic modes propagate at high frequencies. For open-air penstocks, the first acoustic mode begins to propagate at an angular frequency of $\left(\beta_{01} c_{T} / r_{i}\right)$, where $\beta_{01}$ is the first positive root of the Bessel function $\mathrm{J}_{0}(=2.40483)$. For example, the lower cut-off frequency of the first acoustic mode of a penstock of radius $r_{i}=1.75 \mathrm{~m}$ is equal to $2038.25 \mathrm{rad} / \mathrm{s}$ (or $324.4 \mathrm{~Hz}$ ).

In the low-frequency range solution of Eq. (4.1), the tube mode with the lowest propagation velocity at low frequencies is the longitudinal compression mode in water (called water hammer or Young mode), while the higher propagation velocity 
corresponds to the axial stress wave mode in the steel walls of liners and penstocks (called precursor or Lamb mode). The axial stress waves result from the coupling of the radial expansion and contraction of the liner or penstock walls and the Poisson's ratio of the steel. The stress waves in return generate pressure fluctuations in the enclosed water. This coupling is known as the "Poisson coupling" (Skalak, 1956). Tijsseling et al. (2008) re-calculated the solution of Skalak's four-equation model and gave an analytical expression for water hammer and precursor quasi-static wave speeds in open-air penstocks. The general solution of the Poisson coupling problem has been solved exactly by Li et al. (2003) and Tijsseling (2003).

Tijsseling (1996) has classified the one-dimensional FSI models according to their basic equations and physical variables involved to derive their dispersion equations. According to this classification and by ignoring the radial movement of water, the Kuiken model can be considered as a six-equation model (3-mode solutions) where the unknown variables are: the pressure and axial velocity of water, axial stress, axial velocity, hoop stress, and radial velocity in the steel liner or penstock wall.

The wave speed results of the two tube modes (water-hammer and precursor modes) and the first acoustic mode, evaluated according to Eqs. (4.1) and (4.6), are shown in Fig. 4 for steel-lined pressure tunnels with the following parameters: $r_{i}=1.75 \mathrm{~m}, b=100, \rho_{s}=7850 \mathrm{~kg} / \mathrm{m}^{3}, \rho=\rho_{0}=\rho_{w}=1000 \mathrm{~kg} / \mathrm{m}^{3}, E_{s}=210000 \mathrm{MPa}, f_{y}=580 \mathrm{MPa}, \rho_{r}=2200 \mathrm{~kg} / \mathrm{m}^{3}, E_{c}=E_{\mathrm{rm}}=21000$ $\mathrm{MPa}, E_{\mathrm{crm}}=10500 \mathrm{MPa}, \zeta=10 \%, \mu=\kappa=0, \sigma_{l}^{0}=0$, and $\sigma_{r}^{0}=0.5 f_{y} t_{s}$. It can be seen (Fig. $\left.5(\mathrm{~b})\right)$ that the motion of the liner wall is primarily radial for the water hammer mode and primarily longitudinal for the precursor mode. The logarithmic decrement coefficients plotted versus $\omega$ are shown in Fig. 5(a). The radial and longitudinal mechanical coefficients of the surrounding rock mass are taken as follows:

$$
\left\{\begin{array}{l}
M_{r}=M_{l}=\rho_{r}\left(r_{f}-r_{c}\right) \\
K s_{r}=K s_{l}=\frac{p_{c}}{u_{r}^{s}\left(r=r_{c}\right)} \text { of Case 3, } \\
C_{r}=C_{l}=2 \zeta M_{r} \sqrt{K s_{r} / M_{r}}
\end{array}\right.
$$

where $\zeta$ is the damping ratio of the mechanical model, $\rho_{r}$ is the unit mass of the rock mass, and where the inactive rock zone is considered at radius $r=r_{f}$.

For the water hammer mode, the group velocity is below the phase velocity for all $\omega$ values except in the narrow frequency band 1700-1900 rad/s. The group velocity represents then the wave speed of the propagating energy and can be compared to quasi-static wave speed, $a$, and to the speed of sound in unconfined water, $c_{T}$. For frequencies lower than $800 \mathrm{rad} / \mathrm{s}$, the relative difference, $\left(c_{g 1}-c_{0 e q}\right) / c_{g 1}$, between the group velocity, $c_{g 1}$ and $a$ is less than $5 \%$. This difference increases considerably and reaches $150 \%$ for $\omega=1700 \mathrm{rad} / \mathrm{s}$. A cut-off frequency band exists around $2000 \mathrm{rad} / \mathrm{s}$. The water hammer mode starts to propagate again in the high-frequency range (higher than $2250 \mathrm{rad} / \mathrm{s}$ ) with a group velocity that goes up from $500 \mathrm{~m} / \mathrm{s}$ to reach asymptotically $c_{T}$. Near $1700 \mathrm{rad} / \mathrm{s}$, the maximum attenuation coefficient is reached.

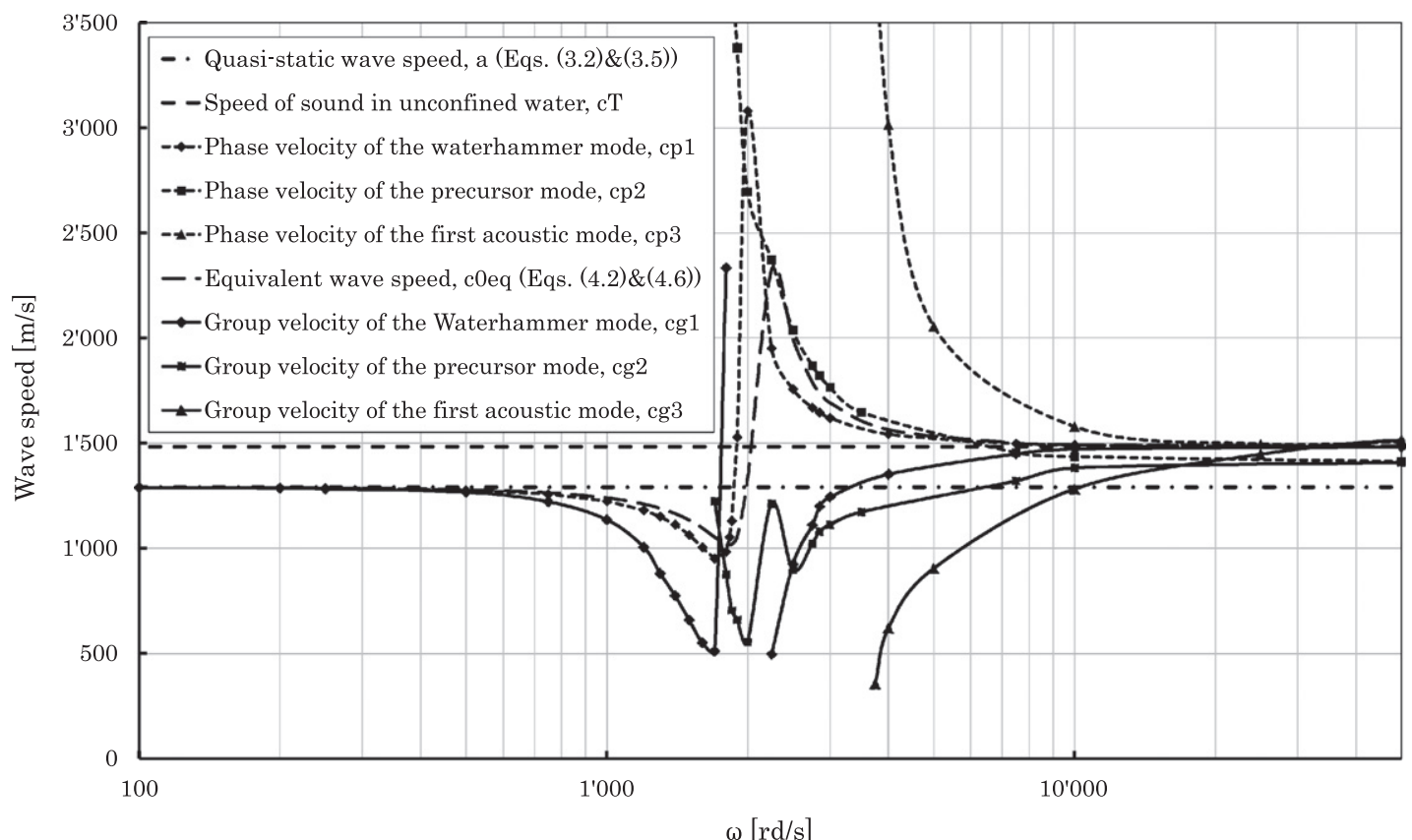

Fig. 4. Three modes' phase and group wave speeds as a function of the angular frequency $\omega$ for an isotropic steel-lined tunnel having the input parameters shown in Section 4.1. The speed of sound in unconfined water, the wave speeds calculated according to quasi-static and equivalent reference approaches are also shown. 

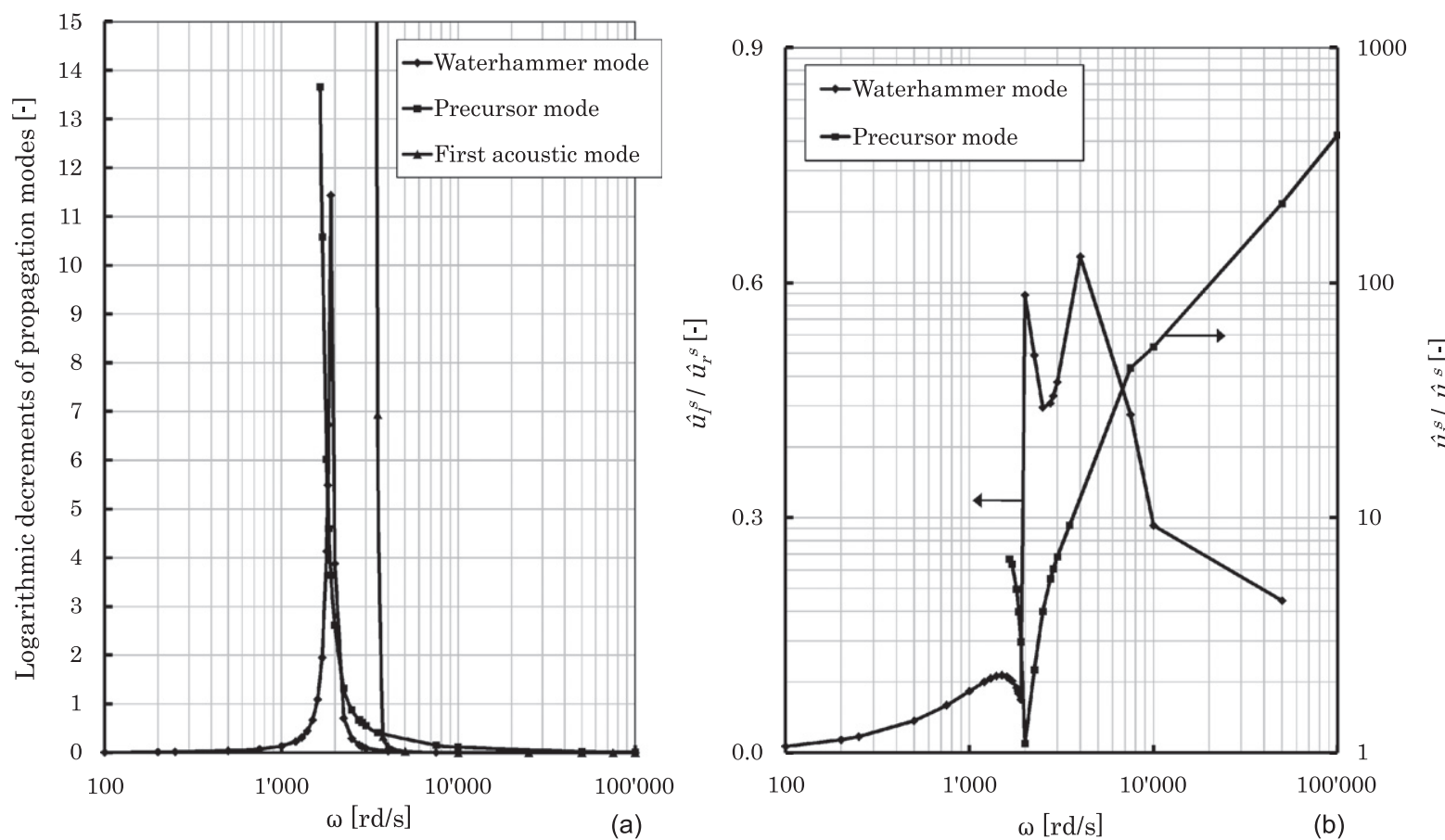

Fig. 5. (a) The logarithmic decrement coefficients (Eqs. (4.6)) of the three propagation modes shown in Fig. 4. (b) The amplitude ratios of the longitudinal to radial displacements $\left(\hat{u}_{l}{ }^{s} / \hat{u}_{r}{ }^{s}\right)$ of the liner wall for the two tube modes shown in Fig. 4.
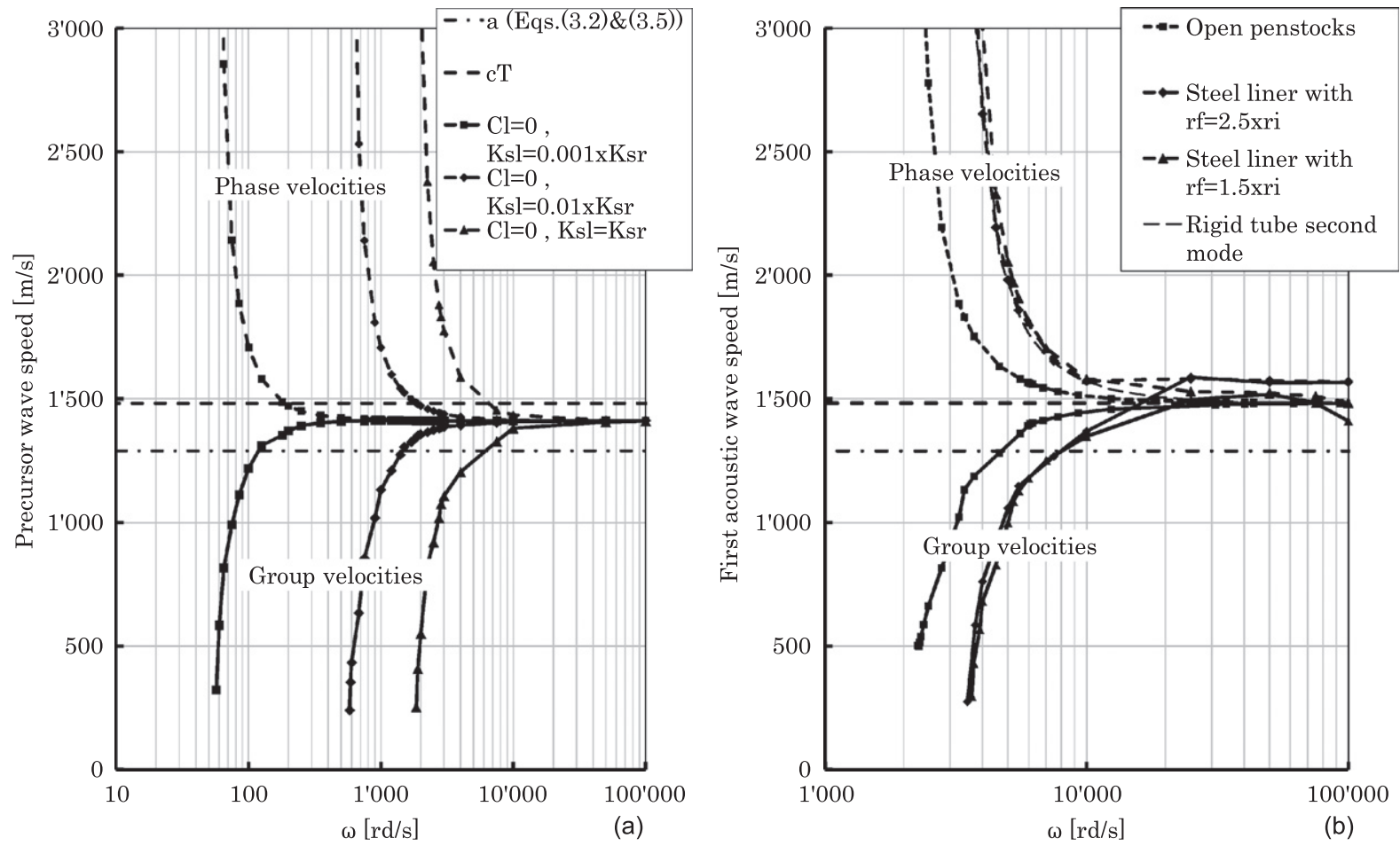

Fig. 6. (a) The variation of the precursor phase and group wave speeds (Eqs. (4.1) and (4.6)) versus $\omega$ for different longitudinal stiffness constraints of a steel liner with $C_{l}=0$ and with the other input parameters similar to those shown in Section 4.1. (b) The variation of the first acoustic phase and velocity wave speeds (Eqs. (4.1) and (4.6)) versus $\omega$ for different radial stiffness constraints characterized by two different values of the internal radius of the crack rock zone $\left(r_{f}\right)$ and with the other input parameters similar to those shown in Section 4.1. 
For the precursor mode, the low cut-off frequency is around $1600 \mathrm{rad} / \mathrm{s}$ and the wave speed (equal to the group velocity) decreases rapidly when $\omega$ increases in the intermediate frequency range (between 1600 and $2000 \mathrm{rad} / \mathrm{s}$ ) and reaches, for large $\omega$, a rather constant value between the quasi-static and $c_{T}$ wave speeds. Fig. 6(a) shows the variation of the precursor wave speed mode (phase and group velocities) as a function of $\omega$ for $C_{l}=0$ and $K s_{l}=0.001 K s_{r}, 0.1 K s_{r}$ and $K s_{r}$. The cut-off frequency depends on the longitudinal stiffness constraint of the liner and can be used as an indicator to detect the presence and intensity of such constraint.

The first acoustic mode begins to propagate at an angular frequency near $3300 \mathrm{rad} / \mathrm{s}$. This frequency is 1.7 times higher than in open-air penstocks. This cut-off frequency depends on the radial constraint of the steel liner (Fig. 6 (b)) and varies close to the second mode of rigid tubes $\left(\beta_{11} c_{T} / r_{i}=3247.6 \mathrm{rad} / \mathrm{s}\right) . \beta_{11}$ is the first positive root of the Bessel function $\mathrm{J}_{1}\left(\beta_{11}=3.83171\right)$. The phase and group velocities of this mode approach $c_{T}$ when $\omega$ becomes very high.

\subsection{FSI problem in the case of open-air penstocks}

For open-air penstocks $\left(K_{r}=0\right)$, Eq. (4.2) becomes equal to (3.10) when $\lambda_{3}$ is equal to $\left(1-v_{s}^{2}\right)$. The solutions of Eq. (4.1) for the two tube modes and the first acoustic mode are given in Fig. 7. The water hammer mode has a cut-off frequency equal to $\left(1 / r_{i}\right)\left(E_{s} / \rho_{s}\right)^{0.5}$. The precursor mode propagates for all values of $\omega$ and is very well estimated by Skalak's formula for frequencies lower than $1200 \mathrm{rad} / \mathrm{s}$ and higher than $7500 \mathrm{rad} / \mathrm{s}$. In the intermediate frequency range the maximum relative difference, $\left(c_{g 2}-a_{\text {Skalak }}\right) / c_{g 2}$, can reach $20 \%$. The first acoustic mode presents a lower cut-off frequency equal to 2038.25 rad/s $\left(=\beta_{01} c_{T} / r_{i}\right)$.

The classical expression (3.10) of the quasi-static wave speed has been also modified by Stuckenbruck et al. (1985). They ignore radial inertia and consider only the axial inertial forces in the pipe wall. This approach leads to a constant real wave velocity and causes a reduction of the classical wave speed of about $7 \%$ for high values of $\left(2 r_{i} / t_{s}\right)$.

For thin-walled viscoelastic pipes, a complex-valued and frequency-dependent wave speed has been formulated by Suo and Wylie (1990b). The classical expression (3.10) was extended by replacing $E_{s}$ by a complex frequency-dependent Young's modulus, $E_{s}(w)$, of the viscoelastic material.

\subsection{FSI problem in the case of unlined pressure tunnels}

As can be seen from Eq. (2.30), the properties of the surrounding materials are included in $\mathrm{K}_{r}^{\prime}$ and $\mathrm{K}_{l}^{\prime}$ expressions. For unlined pressure tunnels in rigid rock mass, $K_{r}^{\prime}$ and $K_{l}^{\prime}$ goes to infinity (similar to a strongly constrained liner), resulting in the

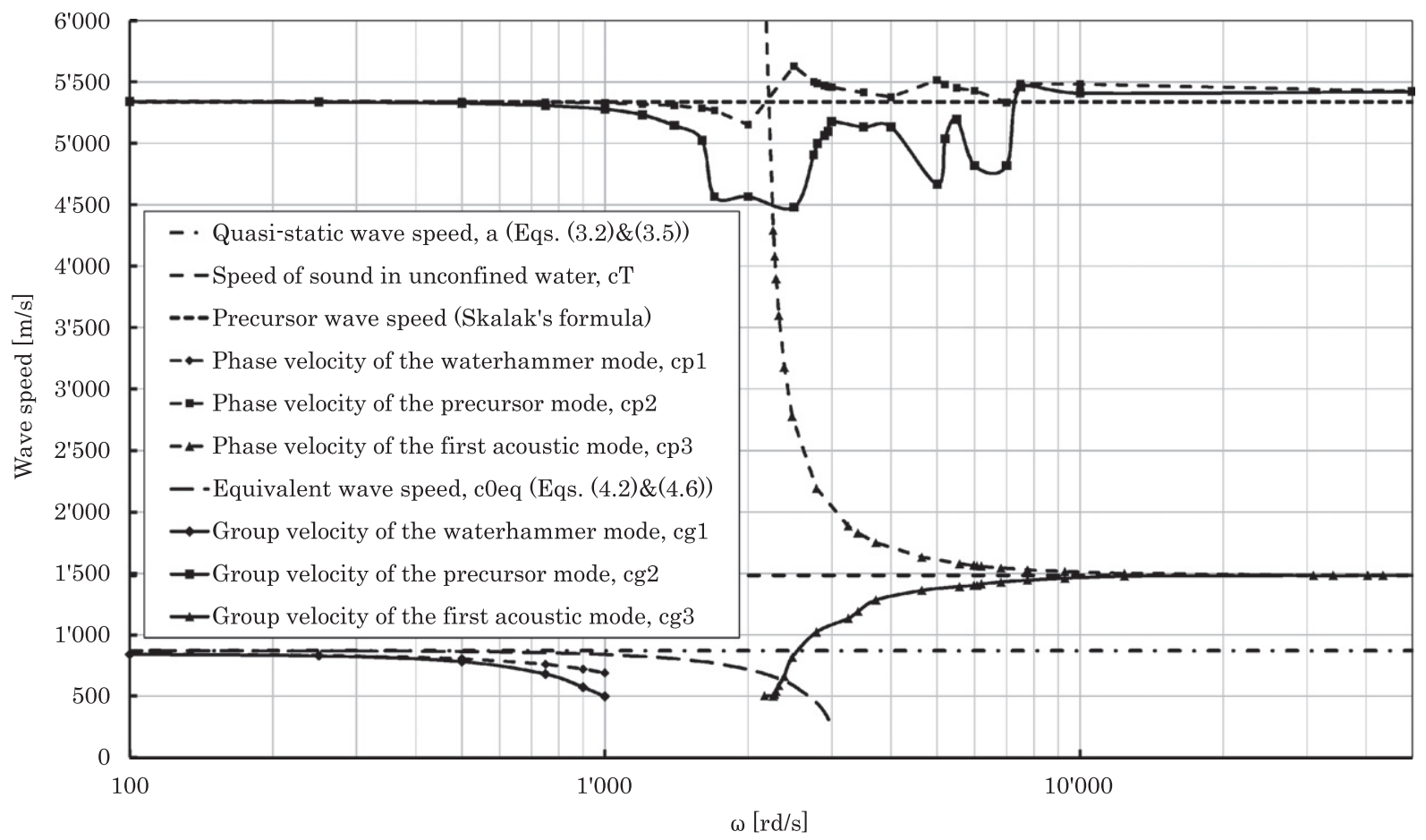

Fig. 7. Comparison between the variation of the quasi-static wave speed, the speed of sound in unconfined water, the equivalent reference wave speed, and the phase and group wave speeds of the three propagation modes versus the angular frequency for an open-air penstock having the input parameters shown in Section 4.1 . 

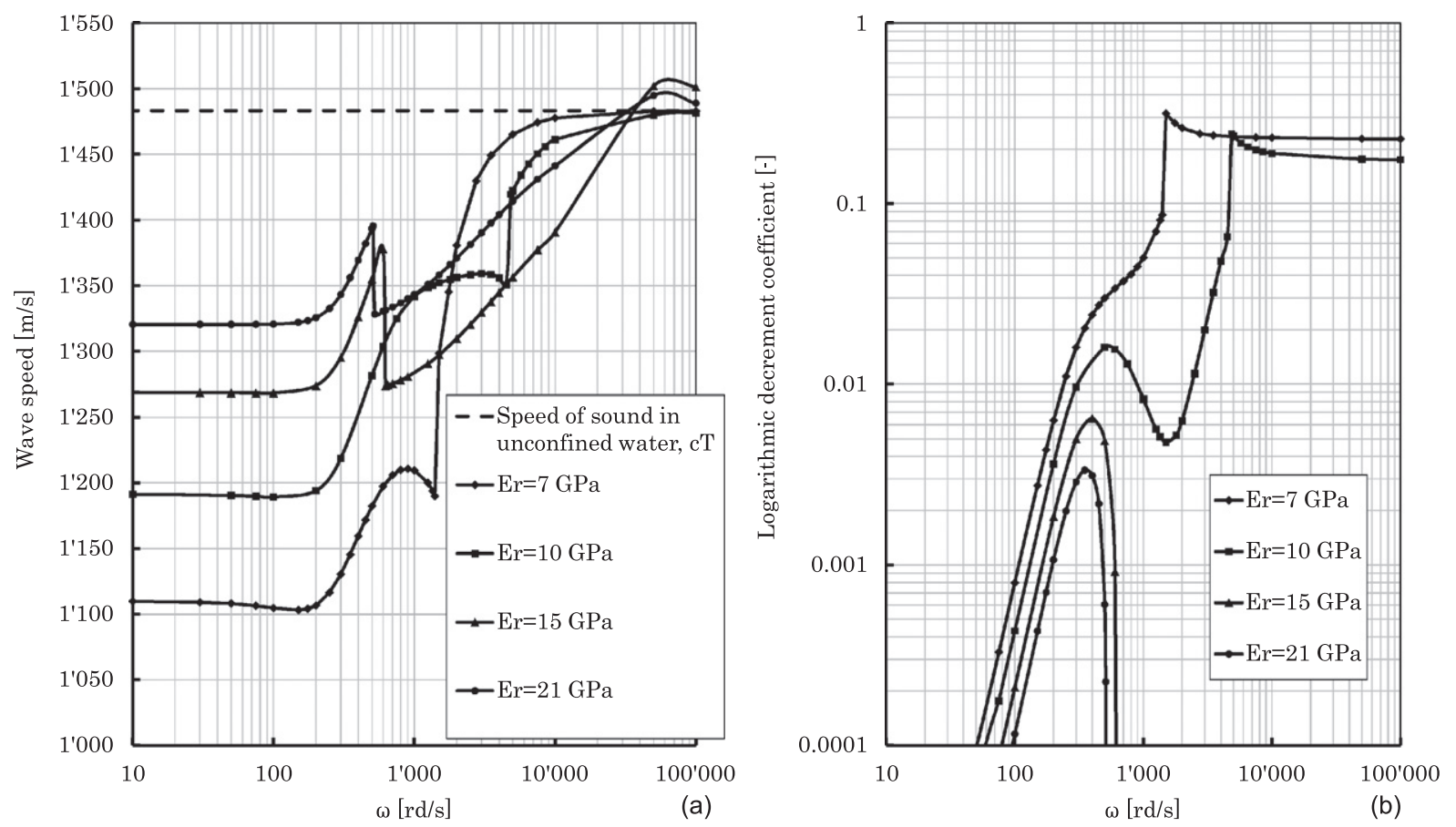

Fig. 8. The variation of: (a) the water-hammer wave speed (Eqs. (4.1) and (4.6)). (b) The logarithmic decrement coefficient (Eq. (4.6)) versus the radial frequency in an unlined pressure tunnel having the following input parameters: $r_{i}=1.75 \mathrm{~m}, \rho_{r}=2200 \mathrm{~kg} / \mathrm{m}^{3}, E_{\mathrm{rm}}=7000,10000,15000$, and $21000 \mathrm{MPa}$

rigid dispersion approximation written as follows:

$$
\left(\beta^{2} k^{2}-\beta^{2} / \Phi_{1}\right) F_{1}\left(i\left(\beta^{2} k^{2}-\beta^{2} / \Phi_{1}\right)^{0.5} 1\right)-\beta^{2} k^{2} F_{1}\left(i\left(\beta^{2} k^{2}-\mathrm{i}^{3} \alpha^{2}\right)^{0.5} 1\right)=0 .
$$

In this case, the propagation modes are only acoustic and occur because the fluid is compressible. The roots of Eq. (4.8)) are

$$
c_{j}=\omega r_{i}\left(\left(\omega r_{i} / c_{T}\right)^{2}-\beta_{1 j}^{2}\right)^{-0.5} \quad j=0,1,2, \ldots,
$$

where $\beta_{1 j}$ is the $j$ th positive root of the Bessel function $\left(\mathrm{J}_{1}\right)$. The reference velocity $c_{0}$ given in (4.2) becomes equal to the wave speed $c_{T}$ which is the first root $(j=0)$ of Eq. (4.9).

The hydraulic transients in unlined pressure tunnels have been studied by Fanelli (1973) and Suo and Wylie (1990a) without considering the complete FSI problem. The rock mass has been treated as an infinite homogeneous and isotropic cylinder and only the dynamic effect of the rock mass has been taken into account. This leads to a complex-valued and frequency-dependent wave speed. Fig. 8(a) and (b) shows, respectively, the variation of the equivalent wave speed and the logarithmic decrement coefficient (Eq. (4.6)) versus the radial frequency in an unlined pressure tunnel with the following input parameters: $r_{i}=1.75 \mathrm{~m}, \rho_{r}=2200 \mathrm{~kg} / \mathrm{m}^{3}$, and $E_{\mathrm{rm}}=7000,10000,15000$, and $21000 \mathrm{MPa}$. The equivalent wave speeds are bounded between the quasi-static (Eq. (3.12)) and the $c_{T}$ wave speeds and have no cut-off frequencies. They decrease slightly at low frequencies, increase rapidly when $\omega$ increases with abrupt change of value at intermediate frequencies, and approach asymptotically $c_{T}$ when the frequency goes to infinity. The decrement coefficient increases rapidly for $\omega$ between 50 and $100 \mathrm{rad} / \mathrm{s}$ and reaches its maximum value for $\omega$ around 300 and $400 \mathrm{rad} / \mathrm{s}$ for hard rock. For relatively weak rock, the coefficient continues increasing with increasing $\omega$, and reaches a constant value at high frequency.

\section{Conclusion}

General expressions for computing wave speeds in steel-lined pressure tunnels have been reformulated, analyzed, and compared for cracked or uncracked concrete and rock layers and for three different moduli of the far-field rock zone. The following assumptions have been considered: (i) frictionless and axisymmetrical waterways, (ii) linearization of equations of water motion, (iii) linear elastic behaviour of the steel-liner and pipe wall, and (iv) infinitely long waterways.

Compared to the "complete quasi-static expression" (Eqs. (3.2) and (3.5)), the wave speed in steel-lined pressure tunnels with cracked backfill concrete and uncracked near-rock zone (Eqs. (3.2) and (3.4)) is overestimated by $4 \%$ for thin steel liners and by $1.5 \%$ for thick steel liners. If all layers are uncracked (Eqs. (3.2) and (3.3)), the wave speed is overestimated up to $8 \%$ for thin steel liners and up to $2.5 \%$ for thick steel liners. The highest differences are observed for relatively weak rock mass moduli. The "complete quasi-static expression" was also compared to other formulas in the literature. For thin steel liners and weak rock mass modulus, Jaeger's and Parmakian's relationships (Eqs. (3.6) and (3.8), respectively) overestimate the water 
hammer velocity (Eqs. (3.2) and (3.5)) by approximately 3-4.5\%, while in Halliwell's formula (Eq. (3.9)) this overestimation reaches $7.5 \%$. For practical applications, this can be tolerated because of the uncertainty in the estimation of the rock mass characteristics and/or the presence of air in the water. Nevertheless, the dynamic pressures obtained from classical water hammer theory are not overly affected by such differences in wave speed. Depending on the system stiffness, FSI may lead to higher extreme dynamic pressures with higher frequencies. Then an enhanced calculation model is required.

Based on Kuiken's (1984) work, the FSI problem with the phase, group and reference wave velocities (Eqs. (4.2) and (4.6)) has been analyzed. The dispersion equation was also solved through a numerical example. The phase and group velocities of the water-hammer mode, precursor mode, and first acoustic mode were evaluated in function of the angular frequency of the transient excitation.

For the water-hammer mode inside steel-lined pressure tunnels and open-air penstocks, FSI results show that the equivalent reference velocity is a good approximation of the phase and group velocities in low $(80 \mathrm{~Hz})$ and high $(800 \mathrm{~Hz})$ frequency ranges with no significant wave attenuations. In the intermediate-frequency range, the maximum relative difference of the wave velocities in steel-lined tunnels relative to the quasi-static case reaches $150 \%$, and the maximum attenuation coefficient is reached. In the intermediate frequency range, the precursor mode has a cut-off frequency and decreases rapidly when $\omega$ increases from 255 to $320 \mathrm{~Hz}$. This mode reaches, for large $\omega$, a constant value between the quasistatic wave speed and speed of sound in unconfined water, $c_{T}$. The cut-off frequency is dependent on the longitudinal distribution of the stiffness of the liner. It can be used as an indicator to detect the presence and intensity of such local weak stiffness. In the case of open-air penstocks, the water-hammer mode presents a high cut-off frequency around $150 \mathrm{~Hz}$, while the precursor mode propagates for all values of the angular frequency $(\omega)$ and can be well estimated by Skalak's formula.

In steel-lined pressure tunnels, the first acoustic mode begins to propagate at an angular frequency near $3300 \mathrm{rad} / \mathrm{s}$ $(525 \mathrm{~Hz})$. This cut-off frequency depends on the radial constraint of the steel liner and varies closely with the second mode of rigid tubes. The wave velocity of this mode approaches the speed of sound, $c_{T}$, when the angular frequency becomes very large.

For the special case of unlined pressure tunnels with constant wave speed, Jaeger's equation overestimates the wave speed by 3.5\% compared to the "complete quasi-static expression". Another approach was adopted by Suo and Wylie (1990a) considering the rock mass as an infinite homogeneous and isotropic cylinder and taking only the dynamic effect of the rock mass into account. Using the FSI formulations, this paper shows that the equivalent wave speed is bounded between the quasi-static wave speed and the speed of sound in unconfined water and has no cut-off frequencies. It decreases slightly at low frequencies, increases rapidly when $\omega$ increases with abrupt change of value at intermediate frequencies, and approaches asymptotically $c_{T}$ when the frequency goes to infinity. For the numerical cases studied, the decrement coefficient, in the case of hard rock, increases rapidly for small $\omega$, reaches a maximum value, and then decreases. For relatively weak rock, the coefficient continues increasing with increasing $\omega$, approaching a constant value at high frequencies.

In an ongoing research project, laboratory experiments as well as in situ measurements are carried out. These experiments will allow the validation of some cases presented herein and the comparison of a calculated transient event in the time and frequency domains, respectively, as suggested in this paper.

\section{Acknowledgments}

The study is part of the research project HydroNet (Modern methodologies for the design, manufacture and operation of pumped storage plants) funded by the Swiss Competence Center Energy and Mobility (CCEM-CH), the Swiss Electric Research and the Swiss Office for Energy.

\section{References}

Atabeck, H.B., 1968. Wave propagation through a viscous fluid contained in a tethered initially stressed, orthotropic elastic tube. Biophysics Journal $8,626-649$.

Bürmann, W., 1975. Water hammer in coaxial pipe systems. ASCE Journal of the Hydraulics Division 101, 699-715.

Chaudhry, M.H., 1987. Applied hydraulics transients, 2nd edition. Van Nostrand Reinhold Company, New York.

Fanelli, M., 1973. Hydraulic resonance in rock-bored penstocks. Water Power September, 342-346.

Flügge, W., 1973. Stresses in Shells, 2nd edition Springer-Verlag, Berlin.

Ghidaoui, M.S., Zhao, M., Mclnnis, D.A., Axworthy, D.H., 2005. A review of water hammer theory and practice. Applied Mechanics Reviews 58, 49-76.

Hachem, F., Schleiss, A., 2009. The design of steel-lined pressure tunnels and shafts. The International Journal on Hydropower \& Dams 16, $142-151$.

Halliwell, A.R., 1963. Velocity of a waterhammer wave in an elastic pipe. ASCE Journal of the Hydraulics Division 89, 1-21.

Jaeger, C., 1933. Théorie générale du coup de belier: application au calcul des conduites à caractéristiques multiples et des chambers d'équilibre. Dunod, Paris.

Jaeger, C., 1972. Rock Mechanics and Engineering. Cambridge University Press.

Jaeger, C., 1977. Fluid Transients in Hydro-Electric Engineering Practice. Blackie \& Son Limited, Glasgow and London.

Kuiken, G.D.C., 1984. Wave propagation in fluid lines. Applied Scientific Research 41, 69-91.

Kuiken, G.D.C., 1988. Amplification of pressure fluctuations due to fluid-structure interaction. Journal of Fluids and Structures 2, 425-435.

Lavooij, C.S.W., Tijsseling, A.S., 1991. Fluid-structure interaction in liquid-filled piping systems. Journal of Fluids and Structures 5, 573-595.

Li, Q.S., Yang, K., Zhang, L., 2003. Analytical solution for fluid-structure interaction in liquid-filled pipes subjected to impact-induced water hammer. ASCE Journal of Engineering Mechanics 129, 1408-1417.

Parmakian, J., 1963. Waterhammer Analysis. Dover Publications, Inc., New York.

Rieutord, E., 1982. Transient response of fluid viscoelastic lines. ASME Journal of Fluids Engineering 104, 335-341. 
Rubinov, S.I., Keller, J.B., 1971. Wave propagation in a fluid-filled tube. Journal of the Acoustical Society of America 50, 198-223.

Rubinov, S.I., Keller, J.B., 1978. Wave propagation in viscoelastic tube containing a viscous fluid. Journal of Fluid Mechanics 88, 181-203.

Salah, B., Massouh, F., Kettab, A., Mbangangoye, B., 2001. Célérité de l'onde de coup de bélier dans les conduites enterrées. La Houille Blanche 3/4, 3-17.

Schleiss, A., 1988. Design criteria applied for the Lower Pressure Tunnel of the North Fork Stanislaus River Hydroelectric Project in California. Rock Mechanics and Rock Engineering 21, 161-181.

Skalak, R., 1956. An extension of the theory of waterhammer. Transactions of the ASME 78, 116-195.

Streeter, V.L., 1963. Discussion of Halliwell A.R. 1963 Velocity of a water-hammer wave in an elastic pipe. ASCE Journal of the Hydraulics Division 89, 295-296.

Stuckenbruck, S., Wiggert, D.C., Otwell, R.S., 1985. The influence of pipe motion on acoustic wave propagation. ASME Journal of Fluids Engineering 107, $518-522$.

Suo, L., Wylie, E.B., 1990a. Hydraulic transients in rock-bored tunnels. Journal of Hydraulic Engineering 116, 196-210.

Suo, L., Wylie, E.B., 1990b. Complex wavespeed and hydraulic transients in viscoelastic pipes. ASME Journal of Fluids Engineering 112, 496-500.

Talobre, J.A., 1967. La mécanique des roches et ses applications. Edition Dunod, Paris.

Tijsseling, A.S., 1996. Fluid-structure interaction in liquid-filled pipe systems: a review. Journal of Fluids and Structures 10, 109-146.

Tijsseling, A.S., 2003. Exact solution of linear hyperbolic four-equation system in axial liquid-pipe vibration. Journal of Fluids and Structures 18, 179-196. Tijsseling, A.S., 2007. Water hammer with fluid-structure interaction in thick-walled pipes. Computers and Structures 85, 844-851.

Tijsseling, A.S., Lambert, M.F., Simpson, A.R., Stephens, M.L., Vitkovsky, J.P., Bergant, A., 2008. Skalak's extended theory of water hammer. Journal of Sound and Vibration 310, 718-728.

Timoshenko, S.P., Goodier, J.N., 1970. Theory of Elasticity. McGraw-Hill Book Co., New York, N.Y.

Wylie, E.B., Suo, L., Streeter, V.L., 1993. Fluid Transients in Systems. Prentice Hall, Fascimile Edition. 